\title{
Disrupting the DREAM transcriptional repressor complex induces apolipoprotein overexpression and systemic amyloidosis in mice
}

\author{
Pirunthan Perampalam, ${ }^{1,2}$ Haider M. Hassan, ${ }^{1,3}$ Grace E. Lilly, ${ }^{1,2}$ Daniel T. Passos, ${ }^{1,4}$ Joseph Torchia, ${ }^{1,2,3}$ Patti K. Kiser, ${ }^{4}$ \\ Andrea Bozovic, ${ }^{5,6}$ Vathany Kulasingam, ${ }^{5,6}$ and Frederick A. Dick $k^{1,3,4,7}$ \\ 'London Regional Cancer Program, London Health Sciences Centre, London, Ontario, Canada. ${ }^{2}$ Department of Biochemistry, Western University, London, Ontario, Canada. ${ }^{3}$ Department of Oncology, Western \\ University, London, Ontario, Canada. ${ }^{4}$ Department of Pathology and Laboratory Medicine, Western University, London, Ontario, Canada. ${ }^{5}$ Department of Clinical Biochemistry, University Health Network, \\ Toronto, Ontario, Canada. ${ }^{6}$ Department of Laboratory Medicine and Pathobiology, University of Toronto, Toronto, Ontario, Canada. ${ }^{7}$ Children's Health Research Institute, London, Ontario, Canada.
}

DREAM (ㅁpp, $\underline{\mathrm{R} b-l i k e, ~} \underline{\mathrm{E}} \mathrm{F}$, and $\underline{\mathrm{M} u v B)}$ is a transcriptional repressor complex that regulates cell proliferation, and its loss causes neonatal lethality in mice. To investigate DREAM function in adult mice, we used an assembly-defective p107 protein and conditional deletion of its redundant family member $\mathbf{p 1 3 0 .}$ In the absence of DREAM assembly, mice displayed shortened survival characterized by systemic amyloidosis but no evidence of excessive cellular proliferation. Amyloid deposits were found in the heart, liver, spleen, and kidneys but not the brain or bone marrow. Using laser-capture microdissection followed by mass spectrometry, we identified apolipoproteins as the most abundant components of amyloids. Intriguingly, apoA-IV was the most detected amyloidogenic protein in amyloid deposits, suggesting apoA-IV amyloidosis (AApoAIV). AApoAIV is a recently described form, whereby WT apoA-IV has been shown to predominate in amyloid plaques. We determined by ChIP that DREAM directly regulated Apoa4 and that the histone variant H2AZ was reduced from the Apoa4 gene body in DREAM's absence, leading to overexpression. Collectively, we describe a mechanism by which epigenetic misregulation causes apolipoprotein overexpression and amyloidosis, potentially explaining the origins of nongenetic amyloid subtypes.

\section{Introduction}

Amyloidosis is a disease characterized by the misfolding and aggregation of proteins into ordered $\beta$-sheet fibrils that are deposited extracellularly within organs or tissues (1). Presently, there are over 35 proteins known to be amyloidogenic in humans, which has led to the classification of amyloidosis into different subtypes based on the causative protein and the organs or tissues affected $(2,3)$. Systemic amyloidosis involves multiple organs and/or tissues as a result of protein deposition at distal sites due to circulation (4). Several members of the apolipoprotein family have been associated with systemic amyloidosis, including apolipoprotein A-I (apoA-I), apolipoprotein A-II (apoA-II), and apolipoprotein A-IV (apoA-IV, ref. 5). These proteins are predominantly made in the liver, although their expression has also been reported in the heart and spleen (6-8). ApoA-I and apoA-II are constituents of HDL and are commonly implicated in hereditary amyloidosis (9, 10). ApoA-IV can exist as part of HDL or circulate in a lipid-free state (11-13). Like apolipoprotein E (apoE) and serum amyloid P-component (APCS), apoA-IV was originally considered to be an amyloid signature protein present in many different amyloid pathologies $(14,15)$. However, new mass spectrometry-based

Conflict of interest: The authors have declared that no conflict of interest exists. Copyright: (5) 2021, American Society for Clinical Investigation.

Submitted: June 3, 2020; Accepted: December 29, 2020; Published: February 15, 2021. Reference information: J Clin Invest. 2021;131(4):e140903.

https://doi.org/10.1172/JCl140903. methods of characterizing protein identities have indicated that apoA-IV has amyloidogenic properties, leading to the clinical designation of apoA-IV amyloidosis (AApoAIV) (16). Importantly, the expansion of protein identities in amyloidosis revealed by mass spectrometry creates a more complex landscape of disease etiology and raises new questions on the origins of nonhereditary forms of the disease.

Epigenetic mechanisms often govern gene expression levels in eukaryotic cells. In particular, deposition of nucleosomes containing the histone variant $\mathrm{H} 2 \mathrm{AZ}$ represses gene expression in a number of biological scenarios through its accumulation in target genes (17-19). A key regulator of H2AZ is the DREAM (ㅁp, 마-like, E2F, and MuvB) complex that possesses nucleosome binding activity and is thought to function as a chaperone to deposit H2AZ at its target genes $(17,20)$. DREAM was initially described as a cell cycle regulatory complex that targets proliferation-related genes through a bipartite promoter element composed of a cell cycle homology region (CHR) and a cell cycle-dependent element (CDE) (17, 20, 21). These elements are well conserved in metazoan promoters, and much of our understanding of DREAM regulation is derived from cell proliferation studies in culture $(22,23)$ or development in fruit flies and worms (24-26). In fruit flies, DREAM not only represses transcription, but also associates with MYB-like proteins to serve as a transcriptional activator (27). In mammals, DREAM disassembles upon the initiation of proliferation and is replaced at promoters by MYB-containing complexes that activate transcription (23). For this reason, it is unclear whether DREAM deficiency 
in lower organisms can be related to its physiological role in mammals, particularly because many phenotypes relate to fruit fly-and worm-specific aspects of gonadal development $(21,26)$.

In mammals, under quiescent conditions DREAM is comprised of a DP protein, an RB family protein (either p107 or p130), an E2F, and the MuvB core of proteins (made up of LIN9, LIN37, LIN52, LIN54, and RBBP4, refs. 21, 28). Upon cell cycle entry, DREAM is disassembled and the MuvB core partners with B-MYB to form MYB-MuvB complexes that activate gene expression required for progression through mitosis (28-30). Consequently, mammalian DREAM function has been difficult to study because all of its components have non-DREAM functions, and deletions of their encoding genes in mice have resulted in embryonic or neonatal lethality (31-34). Consequently, much of our knowledge of DREAM function in mammals is largely derived from cell culture experiments investigating proliferative control, leaving its role in mammalian physiology largely unexplored.

To circumvent the early developmental consequences of DREAM loss, we devised a conditional model for inactivation of DREAM in adult mice. We utilized tamoxifen-inducible deletion of the p130-encoding gene (35) in combination with a constitutive p107 mutant that is unable to interact with the MuvB core (36). Therefore, these mice expressed the components of DREAM, but were unable to assemble the complex. We showed that these mice had diminished survival, exhibited symptoms of renal failure, and developed systemic amyloidosis affecting the heart, kidney, liver, and spleen. Transcriptional and proteomic analyses demonstrated that Apoa4 was overexpressed in the liver and apoA-IV was the most abundant protein found in amyloids of these mice. ChIP analyses demonstrated that DREAM was replaced by B-MYB at the promoter of Apoa 4 with a concurrent decreased localization of $\mathrm{H} 2 \mathrm{AZ}$ within the gene body. These data reveal a connection between DREAM, altered epigenetic regulation of hepatic apolipoprotein expression, and development of systemic AApoA-IV amyloidosis.

\section{Results}

Generation of adult DREAM assembly-deficient mice. The early lethality of mice deficient for DREAM components limits insight into DREAM assembly function in mammals. Consequently, we generated a conditional mouse model to disrupt DREAM complex assembly in young adult animals by eliminating the physical contact between the MuvB subunit LIN52 and p107/p130 (Figure 1A). We utilized a previously described missense allele of $R b l 1$ in which the encoded p107 protein is unable to interact with LIN52 (refs. 36, 37 and Figure 1A). Since this mutation leaves p130 available to participate in DREAM assembly, we employed a ubiquitously expressed UBC-Cre-ERT2 system to conditionally delete Rbl2 (that encodes p130) in adult mice and prevent DREAM assembly (ref. 38 and Figure 1A). The inability to assemble DREAM has previously been shown to result in ectopic MYB-MuvB assembly at DREAM-regulated genes, even in growth-arrested conditions (refs. 23, 36 and Figure 1A); therefore, we first sought to determine whether tamoxifen treatment of these mice resulted in DREAM loss and a gain of MYB-MuvB assembly.

For simplicity, we will refer to the mutant allele of p107 as $p 107^{\mathrm{D}}$, the conditional allele of $\mathrm{p} 130$ as $p 130^{f l}$, and its Cre-inactivated form as $p 130^{-}$. At 8 weeks of age, UBC-CreERT2 $p 107^{\mathrm{D} / \mathrm{D}}$ $p 130^{f l / f l}$ mice were injected with tamoxifen (Supplemental Figure 1A; supplemental material available online with this article; https://oi.org/10.1172/JCI140903DS1). We confirmed successful deletion of $p 130$ exon 2 in the brain, heart, liver, kidney, spleen, bone, and tail by PCR at 1 week after injection, and also demonstrated that it persisted 2 years after tamoxifen treatment in $p 107^{\mathrm{D} / \mathrm{D}} \mathrm{p} 130^{-/-}$mice (Supplemental Figure 1, B-D). We next determined the protein levels of both $\mathrm{p} 107$ and p130 in $p 107^{\mathrm{D} / \mathrm{D}} p 130^{f / f t}$ control and $p 107^{\mathrm{D} / \mathrm{D}} \mathrm{p} 130^{-/-}$mice. We prepared cell lysates from the liver and spleen 4 weeks after tamoxifen administration. Western blotting demonstrated that the 130 protein was undetectable in both the liver and spleen of $p 107^{\mathrm{D} / \mathrm{D}} \mathrm{p130^{-/- }}$ mice, further validating successful deletion of $p 130$ (Figure 1B). Additionally, p107 ${ }^{\mathrm{D}}$ protein was detectable in the livers and spleens of $p 107^{\mathrm{D} / \mathrm{D}} \mathrm{p} 130^{f / f l}$ and $p 107^{\mathrm{D} / \mathrm{D}} \mathrm{p} 130^{-/-}$mice.

To validate loss of DREAM assembly in $p 107^{\mathrm{D} / \mathrm{D}} \mathrm{p} 130^{-/-}$mice, we performed ChIP-qPCR assays to interrogate p107 and B-MYB occupancy at the promoter for Mybl2, the gene for B-MYB itself and a known DREAM target $(23,28,30,39,40)$. We designed primer pairs to encompass the CDE and CHR elements at the transcriptional start site (TSS), as well as a $-1 \mathrm{~kb}$ upstream control (Figure 1C). Since p130 is absent in $p 107^{\mathrm{D} / \mathrm{D}} \mathrm{p} 130^{-/-}$mice, we surveyed $\mathrm{p} 107^{\mathrm{D}}$ occupancy and found it present at the Mybl2 promoter in $p 107^{\mathrm{D} / \mathrm{D}} \mathrm{p} 130^{f / f l}$ mice, indicative of some p107-E2F4 binding at the CHR site independent of DREAM (Figure 1C). Occupancy of $\mathrm{p} 107^{\mathrm{D}}$ at this site was diminished in $p 107^{\mathrm{D} / \mathrm{D}} \mathrm{p} 130^{-/-}$mice and this was coupled with a marked increase in B-MYB occupancy, consistent with MYB-MuvB binding and displacing $\mathrm{p} 107^{\mathrm{D}}$-E2F complexes when p130 was no longer able to assemble into DREAM (Figure 1C). We also confirmed DREAM disruption in $p 107^{\mathrm{D} / \mathrm{D}} \mathrm{p} 130^{-/-}$mice using an in vitro promoter pulldown assay that relies on tandem CDE and CHR elements for stable DREAM binding (Supplemental Figure 2A). In these experiments, p130 was detectable on this probe in $p 107^{\mathrm{D} / \mathrm{D}} p 130^{f / f l}$-derived extracts, but not $p 107^{\mathrm{D} / \mathrm{D}} \mathrm{p} 130^{-/-}$ (Supplemental Figure 2B). Furthermore, $\mathrm{p} 107^{\mathrm{D}}$ was undetectable on this probe in either genotype of extract, consistent with its inability to be assembled into DREAM (refs. 36, 37 and Supplemental Figure 2B). Collectively, these data demonstrated that p130 protein expression was missing in $p 107^{\mathrm{D} / \mathrm{D}} p 130^{-/-}$mice, leading to compromised DREAM assembly and its replacement with MYB-MuvB. This suggests that phenotypes from $p 107^{\mathrm{D} / \mathrm{D}} \mathrm{p} 130^{-/-}$ mice will reveal the role of DREAM in adult mammals.

$p 107^{\mathrm{D} / \mathrm{D}}$ p130 ${ }^{-/-}$mice exhibit compromised renal function and disrupted tissue structure in multiple organs. Cohorts of 8-week-old UBC-CreERT2 $p 107^{\mathrm{D} / \mathrm{D}} \mathrm{p} 130^{f / f l}$ mice were injected with a course of tamoxifen $\left(p 107^{\mathrm{D} / \mathrm{D}} p 130^{-/}\right)$and aged alongside tamoxifeninjected $p 107^{D / D} p 130^{f / f l}$ control mice. There was a $16 \%$ reduction in lifespan for $p 107^{\mathrm{D} / \mathrm{D}} p 130^{-/-}$compared with controls that was significantly different (log-rank test, $P=0.0236$, Figure 2A). Lifespan was similar for both male and female mice and their demise was often without prior symptoms. Some $p 107^{\mathrm{D} / \mathrm{D}} \mathrm{p} 13 \mathrm{O}^{-/-}$mice displayed distress characterized by shallow breathing and a disheveled coat at this age, and these "endpoint" mice were euthanized for further investigation. In contrast, $p 107^{D / D} p 130^{f / f l}$ controls experienced classical aging characterized by kyphosis and predictable endpoints. To explore the underlying causes of premature mortality in $p 107^{\mathrm{D} / \mathrm{D}} \mathrm{p} 130^{-/-}$mice, we examined tissues from $\mathrm{p} 107^{\mathrm{D} / \mathrm{D}} \mathrm{p} 130^{-/-}$ 
A Wild type

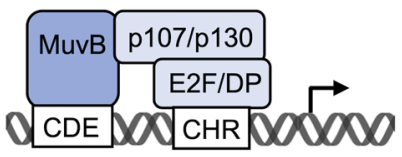

$p 107^{D / D} ; p 130^{f / f}$

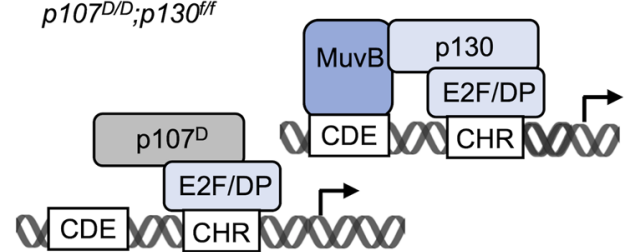

$p 107^{D / D} ; p 130^{-1-}$

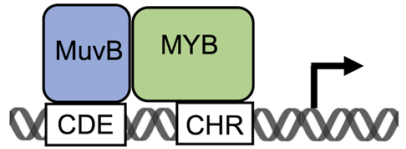

B

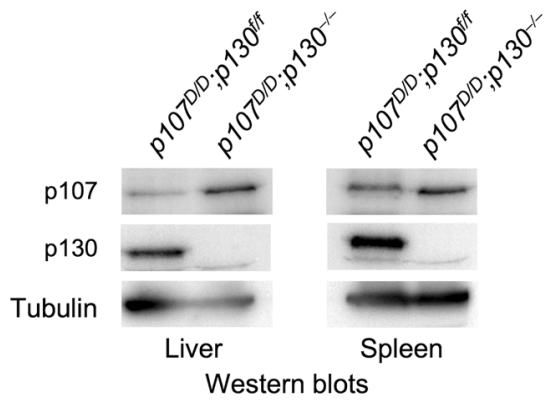

C
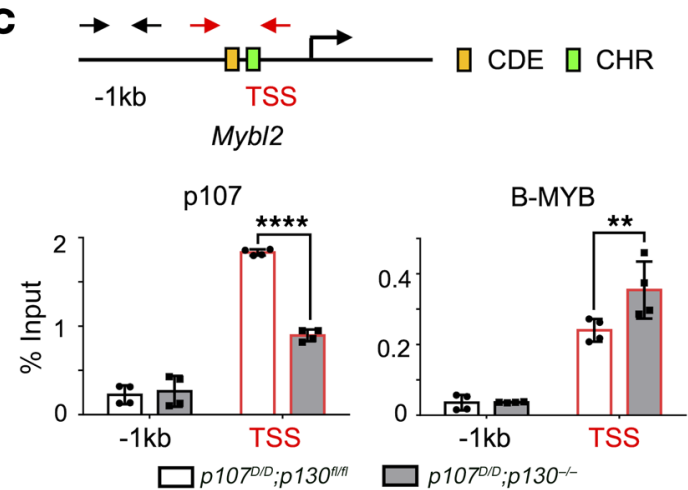

mice at their endpoint and compared them histologically with control mice at the end of their full lifespan. There was little evidence to support ectopic cell proliferation in these mice. Although some $p 107^{\mathrm{D} / \mathrm{D}} \mathrm{p} 13 \mathrm{O}^{-/-}$mice displayed enlarged organs, there were no significant differences in average mass of livers, spleens, or kidneys (Supplemental Figure 3). Examination of H\&E-stained tissues failed to reveal hyperplasia, and Ki67 staining levels and patterns were not altered between genotypes (Supplemental Figure 4). However, H\&E staining revealed abnormalities in the heart, kidney, liver, and spleen of $p 107^{\mathrm{D} / \mathrm{D}} p 130^{-/-}$mice (Figure 2B). Distinctive extracellular, amorphous, hypocellular, and eosinophilic material in these tissues suggested the presence of amyloid fibril deposits. These were found markedly and diffusely in the interstitium of the heart and kidneys, expanding vessel walls in the liver, and on the periphery of the white pulp extending to the red pulp of the spleen (Figure 2B, indicated by arrows).
Figure 1. DREAM assembly is disrupted in $p 107^{0 / 0} p 130^{-/-}$mice. (A) Either one of the RB-like proteins, p107 or p130, can participate in DREAM assembly by binding to MuvB in WT mice and repressing transcription. In $p 107^{/ / 0} \mathrm{p} 130^{+/+}$mice, the $p 107^{\circ}$ mutation prevents it from binding MuvB, rendering $p 107^{\circ}$ unable to participate in DREAM assembly but still able to form p107-E2F complexes at CHR elements. p130 is now the only RB-like family member able to mediate DREAM assembly in $p 107^{0 / 0} \mathrm{p} 130^{+/+}$mice. In $p 107^{0 / 0} \mathrm{p} 130^{-/-}$mice, ablation of $\mathrm{p} 130\left(\mathrm{p} 13 \mathrm{O}^{-/-}\right)$combined with $\mathrm{p} 107^{\circ}$ prevents DREAM assembly. The MuvB core now binds to B-MYB to form MYB-MuvB and activates transcription. (B) Protein extracts were prepared from the livers and spleens of 3 -month-old $p 107^{0 / 0} p 130^{-/-}$and $p 107^{0 / D}$ $p 130^{f / / f l}$ control mice. The expression of $p 107^{D}$ and $p 130$ protein levels was detected by Western blotting, and tubulin served as a loading control. (C) ChIP-qPCR assay to detect $p 107^{\circ}$ and B-MYB binding at the TSS of Mybl2, a known DREAM target. Illustration depicts the primers used for QPCR and the regions of interest: black arrows indicate the negative control 1 $\mathrm{kb}$ upstream of the TSS, and red arrows indicate an approximately $100 \mathrm{bp}$ region surrounding the TSS and containing CDE (blue box) and CHR (green) motifs. Chromatin was prepared from livers, and p107 and B-MYB antibodies were used to precipitate associated DNA ( $n=4$ for each). Graphs show mean quantities of the indicated genome locations precipitated, and error bars indicate 1 SD. Two-way ANOVA was performed for each graph, and significance levels are indicated $\left({ }^{* *} P<0.01 ;{ }^{* * *} P<0.0001\right)$.

The kidneys of $p 107^{\mathrm{D} / \mathrm{D}} \mathrm{p} 130^{-/-}$mice displayed the most visually dramatic deposits with diffusely expanded interstitium, from the cortex to the medulla with variable glomerular involvement (Figure 2B). Importantly, the renal tubular epithelium was swollen due to cytoplasmic vacuolation, consistent with deposition leading to progressive decline in renal function (41-43). Indeed, almost $90 \%$ of endpoint $p 107^{\mathrm{D} / \mathrm{D}} \mathrm{p} 130^{-/-}$mice possessed this type of organ damage, whereas the other affected organs were observed much less frequently (Figure $2 \mathrm{C}$ ). To investigate kidney function, we collected urine from endpoint $p 107^{\mathrm{D} / \mathrm{D}} \mathrm{p} 130^{f / / l}$ and $p 107^{\mathrm{D} / \mathrm{D}} \mathrm{p} 130^{-1-}$ mice and resolved equal volumes of urine by SDS-PAGE to search for evidence of proteinuria (44). All samples showed evidence of murine major urinary proteins (MUPs); however, the urine of $p 107^{\mathrm{D} / \mathrm{D}} \mathrm{p} 130^{-/-}$mice included a prominent approximately $60 \mathrm{kD}$ band that we confirmed by mass spectrometry to be serum albumin (Figure 2D), indicating albuminuria in these mice (45). Last, we tested the serum creatinine level in endpoint mice and determined that it was significantly elevated in $p 107^{\mathrm{D} / \mathrm{D}} \mathrm{p} 130^{-/-}$mice (Figure 2E). These data suggest that at their endpoint, $p 107^{\mathrm{D} / \mathrm{D}}$ $p 130^{-/}$mice exhibited defective kidney function. This is consistent with histological findings in the kidney, and together they indicate kidney failure is the most common ailment in $p 107^{\mathrm{D} / \mathrm{D}} \mathrm{p} 130^{-/}$mice. Because sudden mortality in a portion of $p 107^{\mathrm{D} / \mathrm{D}} \mathrm{p} 130^{-/}$mice prevented physiological and histological investigation, it is possible some $p 107^{\mathrm{D} / \mathrm{D}} \mathrm{p} 130^{-/-}$mice succumbed to a more rapid cause of death such as cardiac arrest. Overall, multiple organs were damaged in $p 107^{\mathrm{D} / \mathrm{D}} \mathrm{p} 130^{-/-}$mice, leading to premature mortality.

Systemic amyloidosis is evident in $p 107^{\mathrm{D} / \mathrm{D}} \mathrm{p} 13 \mathrm{O}^{-/}$mice. We investigated the affected organs for potential amyloid deposition through histological stains and transmission electron microscopy (TEM). Heart, kidney, liver, and spleen tissue sections from $p 107^{\mathrm{D} / \mathrm{D}}$ $p 130^{-/-}$mice were stained with Congo red and examined under bright field optics and polarized light (46-48). This demonstrated that weakly stained eosinophilic material corresponded with regions of apple-green birefringence, a hallmark of amyloid fibril 

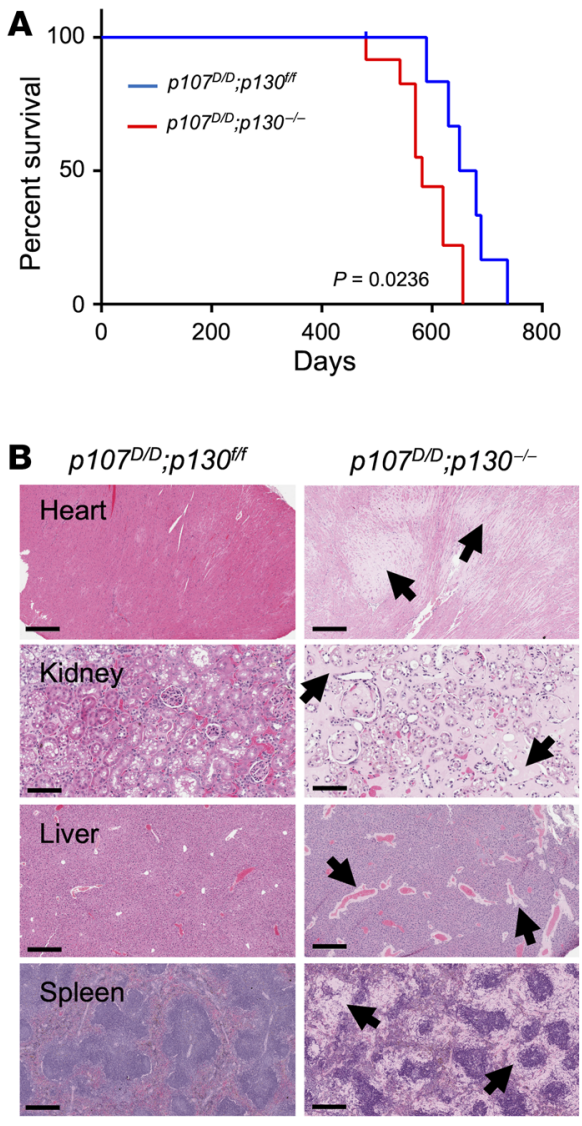

C Frequency of histologic abnormalities
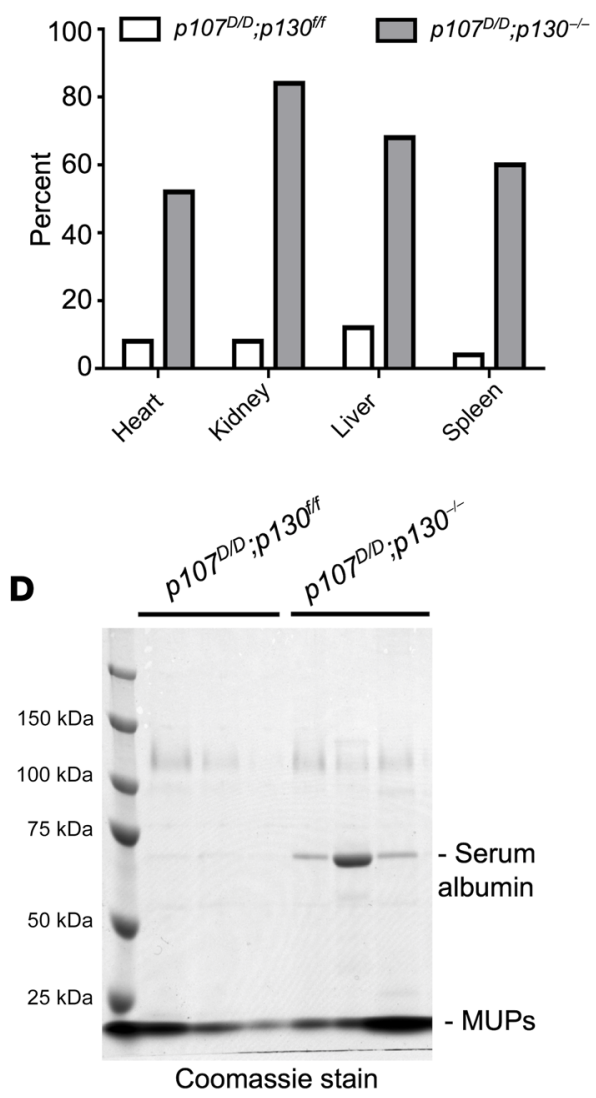

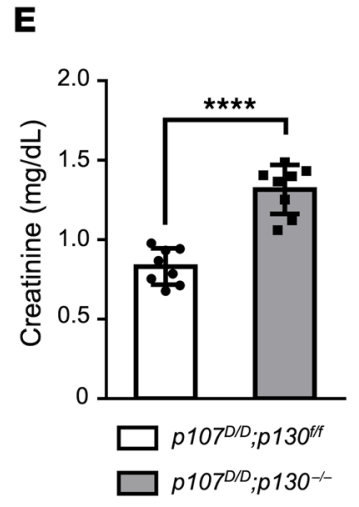

Figure 2. $p 107^{0 / 0} p 130^{-/-}$mice have shortened lifespan and compromised organ function. (A) Cohorts of $p 107^{0 / 0} p 130^{-/-}(n=30)$ and p1070/0 $p 130^{f / / f l}$ control mice $(n=37)$ were aged to humane endpoints. Kaplan-Meier survival plots reveal survival proportions and a log-rank test was used to compare outcomes $(P=0.0236)$. (B) H\&E staining of tissues obtained from $p 107^{0 / 0} p 130^{f / / f l}$ and $p 107^{0 / 0} p 130^{-/-}$mice at endpoint. Examples of poorly staining homogeneous, acellular, eosinophilic areas found in $p 107^{0 / 0} p 130^{-/-}$mice are indicated by arrows. Data are representative of $21 \mathrm{p} 107^{0 / 0} \mathrm{p} 130^{f / / f l}$ and $25 \mathrm{p} 107^{0 / 0} \mathrm{p} 130^{-/-}$mice. Scale bars: $400 \mu \mathrm{m}$ for heart, liver, and spleen. Scale bars: $100 \mu \mathrm{m}$ for kidney. (C) Frequency of histologic abnormalities in $p 107^{0 / 0} p 130^{f / / f l}(n=21)$ and $p 107^{0 / 0}$ $p 130^{-/-}$mice $(n=25)$ for each of the indicated organs. (D) Urine samples were collected from endpoint $p 107^{0 / 0} p 130^{f / / f l}$ and $p 107^{0 / 0} p 130^{-/-}$mice, and proteins were resolved on SDS-PACE gel and stained with Coomassie blue. MUPs, major urinary proteins. (E) Serum samples were collected from endpoint mice and were analyzed for levels of creatinine. Bar graph represents mean quantities for the indicated genotypes, and error bars indicate 1 SD $(n=8)$. **** $P<0.0001$, by Student's $t$ test.

deposition (Figure 3, A-D). The presence of amyloid fibril structures in the medullar regions of kidney tissue was confirmed by TEM from FFPE tissue sections (Figure 3E). Measurement of these medullar amyloid fibrils revealed a mean diameter of $12 \mathrm{~nm}$ that was consistent with amyloidosis (ref. 49 and Figure 3F). We similarly detected fibrils using TEM in heart and liver tissues of $p 107^{\mathrm{D} / \mathrm{D}}$ $p 130^{-/-}$mice (Figure 3, G-H). These experiments confirmed that the disrupted tissue structures observed in the heart, kidney, liver, and spleen of $p 107^{\mathrm{D} / \mathrm{D}} \mathrm{p} 130^{-/-}$mice were amyloid in nature.

We next determined the prevalence and impact of amyloids in $p 107^{\mathrm{D} / \mathrm{D}} \mathrm{p} 130^{-/-}$mice compared with $p 107^{\mathrm{D} / \mathrm{D}} \mathrm{p} 130^{f / f l}$ controls. Heart, kidney, liver, spleen, and brain tissue sections from $p 107^{\mathrm{D} / \mathrm{D}}$ $p 130^{-/-}$and control mice were stained with Congo red and scored to quantitate amyloid deposition based on the quantity of affected area on a scale from 0 to 3 (Supplemental Figure 5). Amyloid deposition scores were plotted for $p 107^{\mathrm{D} / \mathrm{D}} \mathrm{p} 13 \mathrm{O}^{-/-}$and control mice for each age cohort (1-year-old and endpoint mice) (Figure 4A). We also enumerated these amyloid deposition scores with other abnormal histological features, including relative degree of cel- lular degeneration and inflammatory cell infiltrates, and plotted the aggregate score for each mouse on an ordinal scale from 0 to 3 that is representative of the observed diagnostic severity (Supplemental Figure 5 and refs. 50, 51). In heart, kidney, liver, and spleen, $p 107^{\mathrm{D} / \mathrm{D}} \mathrm{p} 130^{-/-}$mice consistently had increased amyloid deposition, cellular degeneration, and inflammation at their endpoint compared with $p 107^{\mathrm{D} / \mathrm{D}} p 130^{f / f l}$ control mice (Figure 4B), and a similar trend was also apparent in comparisons of 1-year-old $p 107^{\mathrm{D} / \mathrm{D}} \mathrm{p} 130^{-/-}$mice and their age-matched controls. Notably, the striking amyloid deposition and other histologic abnormalities found in these tissues were absent from the brain (Figure 4, A and $\mathrm{B}$ and Supplemental Figure 6). Collectively, these results indicate $p 107^{\mathrm{D} / \mathrm{D}} \mathrm{p} 13 \mathrm{O}^{-/-}$mice accumulated extensive amyloid fibril deposition in the heart, liver, kidney, and spleen, leading to defects in normal organ structure and function. These characteristics are indicative of systemic amyloidosis in $p 107^{\mathrm{D} / \mathrm{D}} \mathrm{p} 130^{-/-}$mice.

Apolipoproteins predominate in amyloid fibrils and are overexpressed in $p 107^{\mathrm{D} / \mathrm{D}} \mathrm{p} 130^{-/}$mice. There are more than 35 amyloid subtypes that have been identified in humans $(1,2)$. To relate the 


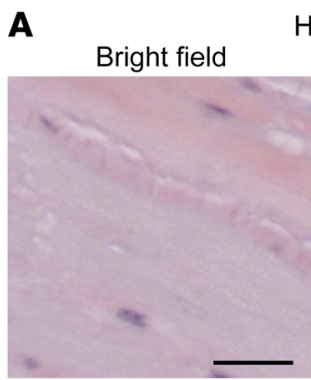

Heart

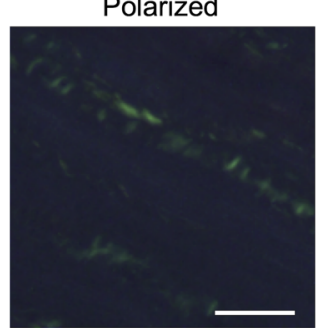

B
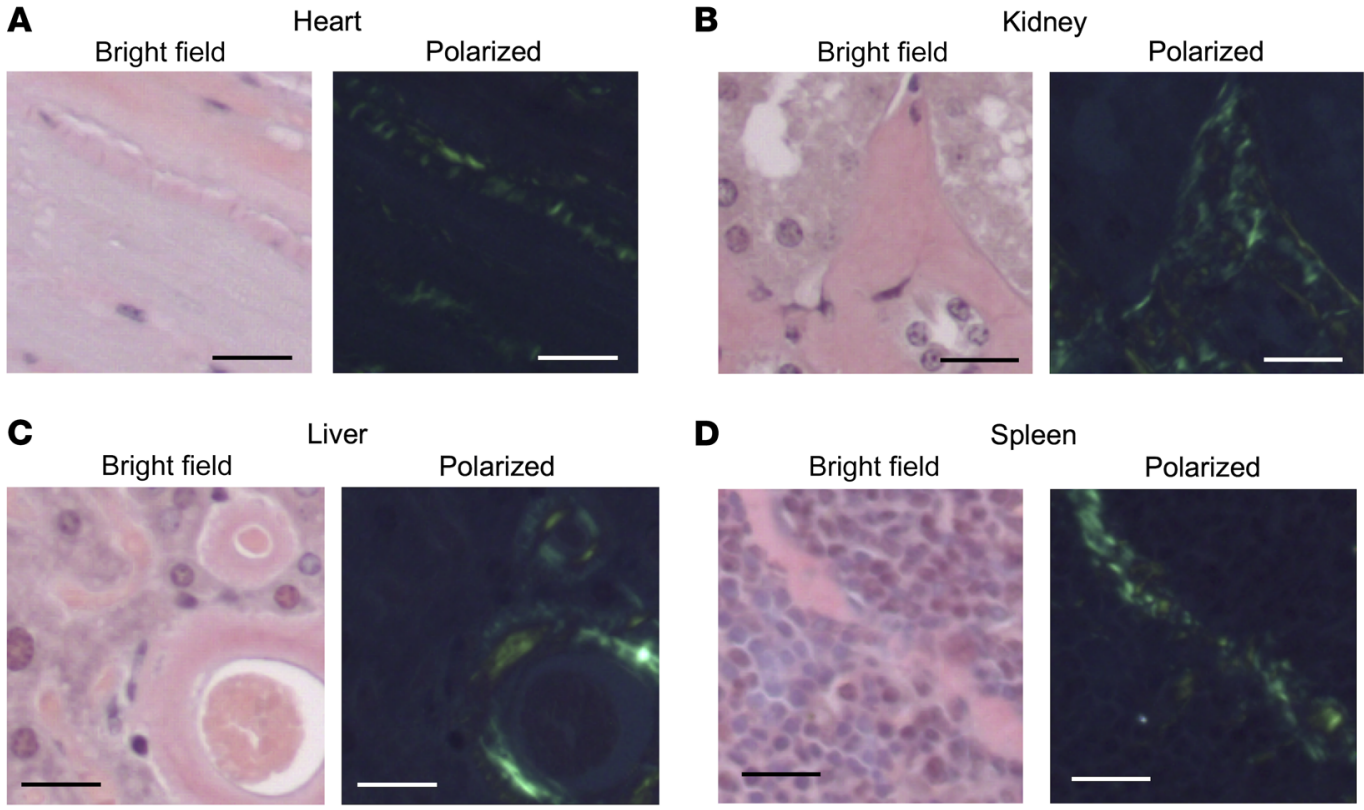

Liver

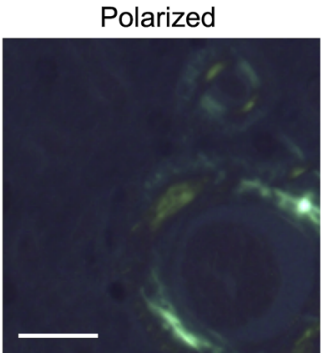

D

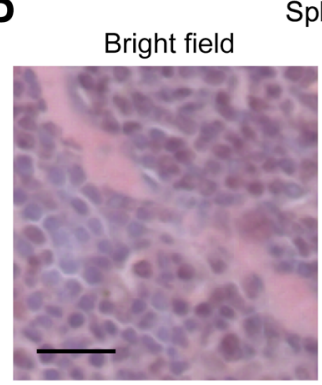

Spleen

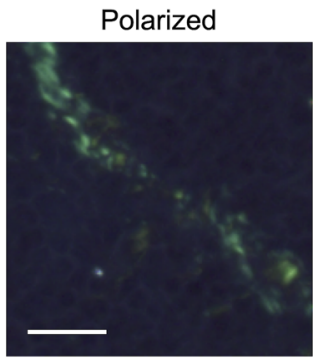

Congo Red
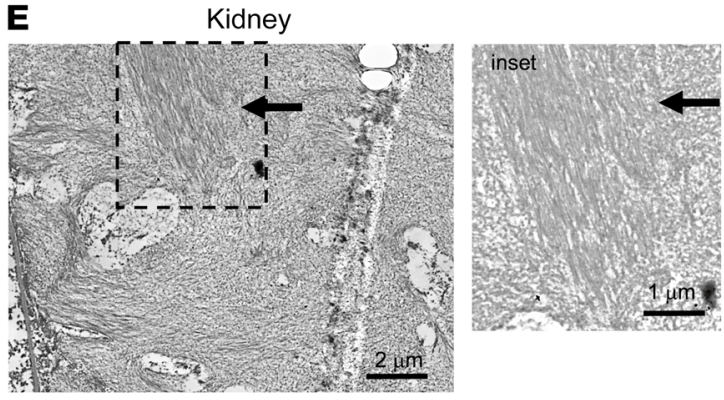

G

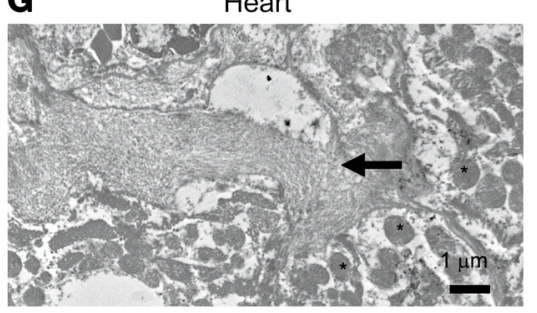

F
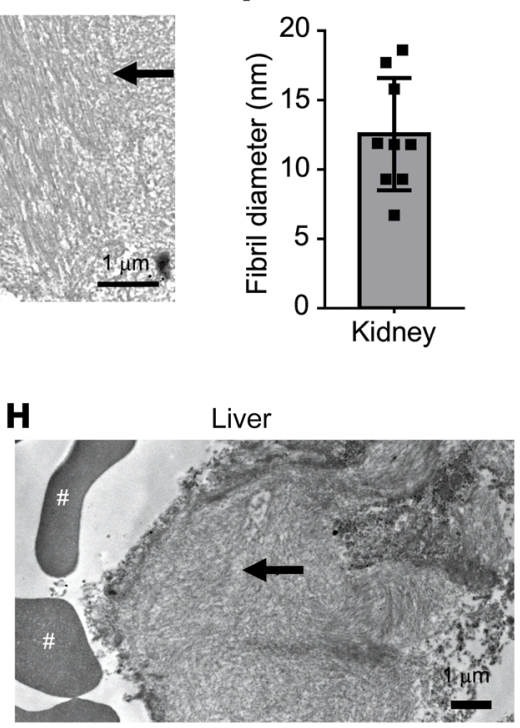

Figure 3. Systemic amyloidosis in $p 107^{0 / 0} \mathrm{p}^{130^{-/-}}$mice. (A-D) Tissue sections of heart (A), kidney (B), liver (C), and spleen (D) from endpoint $p 107^{D / D} p_{130^{-/-}}$mice were stained with Congo red. Bright field images were captured along with corresponding apple green birefringence under polarized light. Scale bars: $20 \mu \mathrm{m}$. (E) FFPE tissues were processed for TEM. Ultrastructure of acellular material in the kidney is shown. Black arrows indicate fibril structure in this organ. Scale bars: $2 \mu \mathrm{m}$ and $1 \mu \mathrm{m}$ (enlarged inset). (F) Fibril diameters in kidney TEM images were measured. Bar graph represents mean diameter obtained from individual fibril measurements, and error bars indicate $1 \mathrm{SD}(n=$ 9). (G-H) TEM images of FFPE heart (G) and liver (H) tissue. Black arrows indicate areas of fibril deposition. For orientation, the asterisk indicates mitochondria in cardiomyocytes, and the pound sign denotes red blood cells in a hepatic capillary. amyloidosis phenotype in $p 107^{\mathrm{D} / \mathrm{D}} \mathrm{p} 130^{-/-}$mice with human clinical subtypes, we utilized fluorescent optics of Congo red-stained tissue to identify amyloid deposits (Figure 5, A and B). We then performed laser-capture microdissection from FFPE tissue sections and used tandem mass spectrometry to determine its protein composition (LMD/MS) (refs. 52-54 and Figure 5C). In LMD/ MS analysis, mutations in amyloid-causing genes correlate with abundance of their encoded proteins in amyloid deposits (52). Combined with the increased specificity enabled by focusing only on the Congo red-stained areas, highly abundant proteins in our analysis might be amyloidogenic in $p 107^{\mathrm{D} / \mathrm{D}} \mathrm{p} 130^{-/-}$mice. Within this proteome, "amyloid signature proteins" were present, which serve as an internal control to denote that amyloid deposition is present. These include apoE, APCS, and possibly clusterin and vitronectin $(52,55,56)$. Therefore, by examining this enriched Congo red-stained proteome for the most abundant proteins pres- ent, we can identify causative protein candidates from the amyloid plaques in $p 107^{D / D} p 130^{-/-}$mice.

LMD/MS analysis was performed on hearts, kidneys, livers, and spleens from endpoint $p 107^{\mathrm{D} / \mathrm{D}} \mathrm{p} 13 \mathrm{O}^{-/-}$mice. This identified a number of known amyloidogenic proteins, as well as common amyloid-accompanying peptides. A representative list of proteins that are known to be causative or associated with amyloidosis in humans and present in an endpoint $p 107^{\mathrm{D} / \mathrm{D}} \mathrm{p} 130^{-/-}$liver is shown (Table 1). Consistent with human clinical cases, the most abundant protein identified in all samples was apoE. Therefore, we normalized spectral counts from each sample to its own apoE and compared the abundance of the remaining amyloidogenic and amyloid-accompanying proteins. Figure 5D shows a heatmap depicting relative spectral counts for each protein across 5 identically microdissected samples. Among the known amyloidogenic proteins, apoA-IV consistently had the highest normalized spec- 

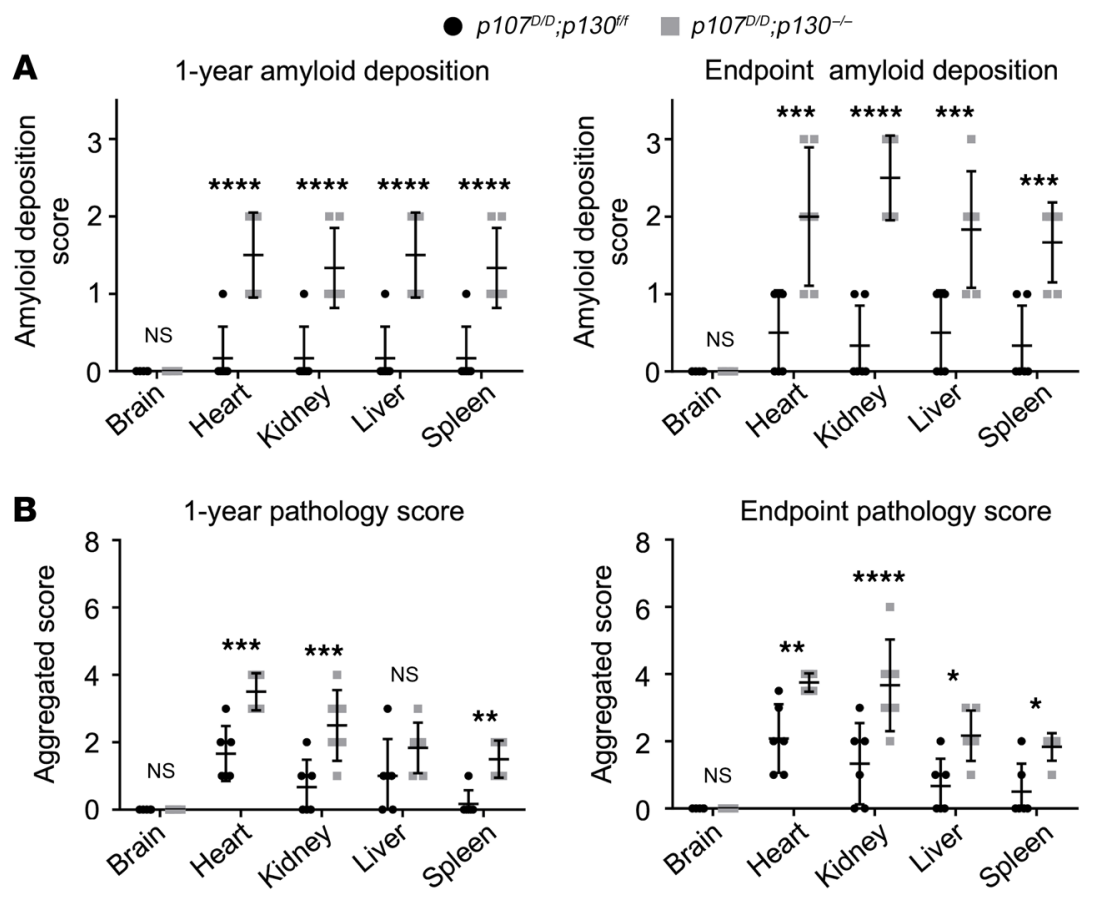

Figure 4. Tissue distribution and disease severity of amyloidosis in $p 107^{0 / 0} \mathbf{p} 130^{-/-}$mice. (A) Tissues from 1-year-old and endpoint mice from $p 107^{D / 0} p 130^{f / f l}$ and $p 107^{0 / 0} p 130^{-/-}$cohorts were scored for amyloid deposition on a scale of $0-3(n=6)$. Average scores were plotted for 1-year-old and endpoint mice and error bars represent $1 \mathrm{SD}$. Means were compared by 2 -way ANOVA and significance levels are indicated $\left({ }^{* *} P<0.001\right.$; ${ }^{* * * *} P<0.0001$; and NS is not significant, $P>0.05$ ). (B) Tissues from 1-year-old and endpoint mice from p1070/0 $p 130^{f / / f l}$ and $p 107^{0 / 0} p 130^{-/-}$cohorts were scored for 3 criteria (amyloid deposition, cellular degeneration, inflammation) on a scale of $0-3(n=6)$. Scores were aggregated for each mouse and plotted. Mean scores are indicated along with $1 \mathrm{SD}$. Means were compared by 2-way ANOVA, and significance levels are indicated $\left({ }^{*} P<0.05\right.$; ${ }^{* *} P<0.01 ;{ }^{* *} P<0.001$; ${ }^{* * *} P<0.0001$; and NS, $P>0.05$ ). tral counts (Figure 5D), followed by apoA-II and apoA-I (Figure 5D). Immunoglobulin light and heavy chains were also detected in most of these samples at relatively low spectral counts (Figure 5D). These data suggest that apolipoproteins were the most likely cause of amyloidosis in $p 107^{\mathrm{D} / \mathrm{D}} \mathrm{p} 130^{-/-}$mice.

Amyloid tissue deposition patterns identified by histological analyses and amyloidogenic proteins identified by LMD/MS in $p 107^{\mathrm{D} / \mathrm{D}} \mathrm{p} 130^{-/-}$mice suggest apoA-IV, apoA-II, or apoA-I, or a combination of these, as the cause of amyloidosis in these mice. Since DREAM is a transcriptional repressor and its loss promotes assembly of the activating MYB-MuvB complex, we investigated expression levels of these apolipoproteins. We performed qPCR analysis of RNA isolated from livers of 3-month-old, 1-year-old, and endpoint $p 107^{\mathrm{D} / \mathrm{D}} p 130^{f / f l}$ and $p 107^{\mathrm{D} / \mathrm{D}} \mathrm{p130^{-/- }}$ mice (Figure 5, E-G). Each of Apoa1, Apoa2, and Apoa4 were found to be overexpressed in at least 1 of the time points investigated. Only Apoa 4 was significantly increased in $p 107^{\mathrm{D} / \mathrm{D}} p 130^{-/-}$mice at all ages of investigation (Figure $5 \mathrm{G}$ ), and its protein levels were approximately 4 -fold increased in liver extracts from 3-month-old $p 107^{\mathrm{D} / \mathrm{D}} \mathrm{p} 130^{-/-}$mice (Figure $5 \mathrm{H}$ ), further suggesting that it is the best candidate to be a causative protein in the amyloidosis observed. In addition, we investigated the expression of amyloid-associated components albumin, APCS, and ApoE. Consistent with an associated role, Alb, Apcs, and Apoe expression in the livers of $p 107^{\mathrm{D} / \mathrm{D}} \mathrm{p}^{130^{-/-}}$mice was unaltered (Supplemental Figure 7).

An alternative interpretation of the LMD/MS data is that, although the spectral counts for immunoglobulin chains were low, they may play a causative role too. Since DREAM is known to function in proliferative control, and immunoglobulin amyloidosis is common in myeloma patients, we investigated this possibility further. We found the expression of Ighm to be significantly increased in the bones and spleens of 1-year and endpoint $p 107^{\mathrm{D} / \mathrm{D}}$ $p 130^{-/-}$mice compared with controls (Supplemental Figure 8). However, a key difference between apolipoprotein- and immu- noglobulin-based amyloidoses in human patients is the presence of amyloid deposits in bone marrow and the gastrointestinal tract (57). H\&E- and Congo red-staining in endpoint $p 107^{\mathrm{D} / \mathrm{D}} \mathrm{p130^{-/- }}$ mice did not identify amyloid deposits in bone marrow, nor did staining reveal the presence of abnormally proliferating plasma cells (Supplemental Figure 9A). Examination of the small intestines of endpoint $p 107^{D / D} p 130^{-/-}$mice stained with Congo red showed scattered amyloid deposits, but nothing distinct by H\&E staining as in the previously described organs above (Supplemental Figure 9B). Overall, the lack of bone marrow amyloids and only minor intestinal amyloids, but prominent cardiac, renal, hepatic, and splenic involvement, was most consistent with an apolipoprotein-derived amyloid condition. In addition, apolipoprotein misexpression and greater detection levels in LMD/MS experiments suggest that they are the more likely cause of amyloidosis in $p 107^{\mathrm{D} / \mathrm{D}} \mathrm{p} 130^{-/-}$mice. Last, the most consistent and highly overexpressed apolipoprotein in the liver was apoA-IV, and its prominent detection in amyloids indicates that it was the most likely source of misexpressed protein to seed amyloid formation.

DREAM disruption leads to H2AZ loss at apolipoprotein genes. Based on MYB-MuvB binding to the Mybl2 promoter upon $p 130$ deletion in our initial characterization of this genetic model, we sought to determine whether DREAM loss misregulated apolipoprotein genes. A genome-wide analysis of predicted CHR and CDE motifs has identified candidates for DREAM/ MYB-MuvB regulation (20). From this data set, Apoa1 and Apoa 4 were found to possess both elements, and others, such as Alb and Apoa2, were found to possess CHR motifs. We performed quantitative ChIP-qPCR assays on chromatin from livers of 3-month-old mice to determine whether DREAM/MYB-MuvB bind any of these promoters (Figure $6, A-D)$. We detected $\mathrm{p} 107^{\mathrm{D}}$ binding to the TSS region of each of these genes in $p 107^{\mathrm{D} / \mathrm{D}} p 130^{f / f l}$ mice. However, the recruitment of $\mathrm{p} 107^{\mathrm{D}}$ was significantly reduced in $p 107^{\mathrm{D} / \mathrm{D}} \mathrm{p} 130^{-/-}$livers at Apoa1 and Apoa4 promoters (Figure 6, A and C). The decrease in $\mathrm{p} 107^{\mathrm{D}}$ 
A

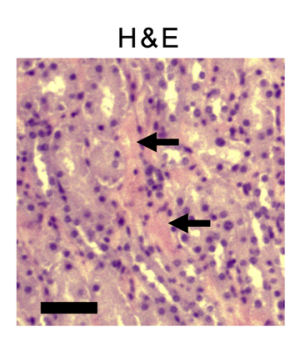

B

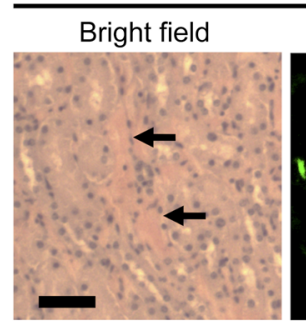

Congo Red

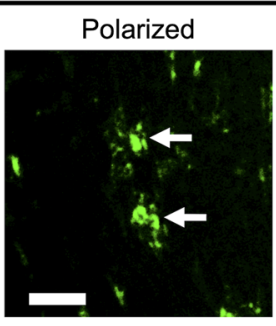

Fluorescence

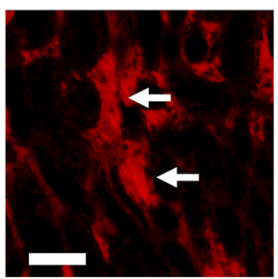

C

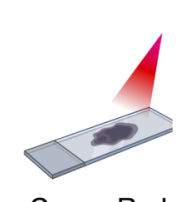

Congo Red stained tissue

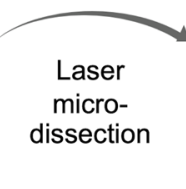

micro-

issection
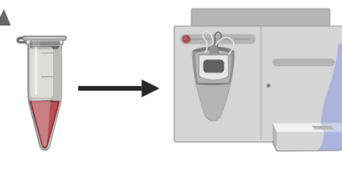

Mass spectrometry

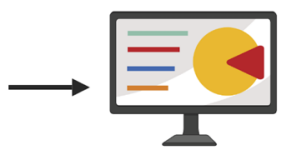

Database matching
D

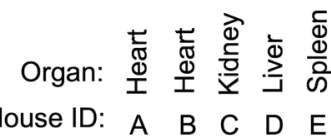

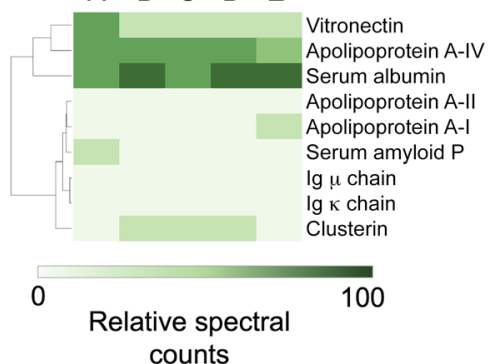

$\mathbf{F}$

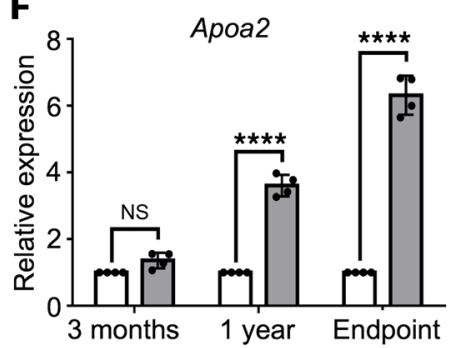

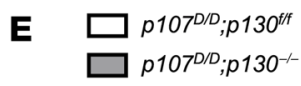

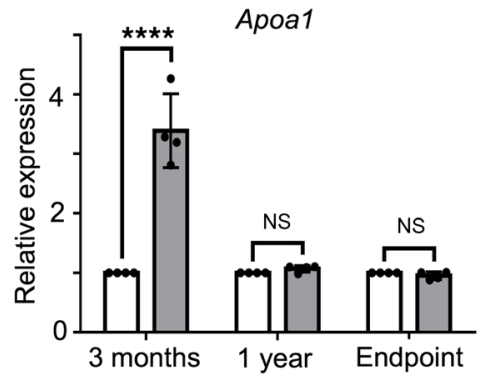

G

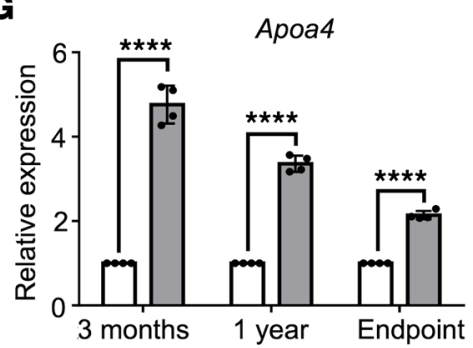

Figure 5. ApoA-IV is the most abundant amyloidogenic protein in $p 107^{D / D} \mathrm{p}^{130^{-/-}}$ amyloid deposits. (A) H\&E staining of kidney from an endpoint $p 107^{0 / 0}$ p130\%- mouse. Arrows indicate acellular eosinophilic material. Scale bar: $50 \mu \mathrm{m}$. (B) Congo red staining of a serial section of the same kidney as in $\mathbf{A}$. Black arrows indicate the same acellular material under bright-field optics as in $\mathbf{A}$. White arrows mark the same locations under polarized and fluorescent optics. Scale bars: $50 \mu \mathrm{m}$. (c) Schematic illustration of LMD/MS procedure: Congo red-positive regions were laser captured and processed for mass spectrometry to identify peptides present in amyloids. (D) Per spectral match quantities were scaled relative to the most abundant protein in each sample, apoE. Rows (proteins) were clustered and values are represented as indicated by the scale at the bottom. Each column represents an organ from an endpoint $p 107^{0 / 0}$ p130 $10^{-/}$mouse. (E-C) Total RNA was used to synthesize cDNA. Gene expression was determined by qPCR in 3-month-old, 1-year-old, and endpoint p107// $p 130^{f / / / 1}$ and $p 107^{/ / 0} p 130^{-/-}$mice and normalized to Gapdh for each age group ( $n=$ 4). Bar graphs show mean expression values for Apoa1 (E), Apoa2 (F), Apoa4 (G) and error bars represent 1 standard deviation. Values are normalized to that of $p 107^{0 / 0} p 130^{f / f / l}$ at each age for each gene. Two-way ANOVA was performed for each gene and significance levels are indicated ${ }^{* * * *} P\langle 0.0001 ; \mathrm{NS}, P\rangle$ 0.05). (H) Protein extracts from the livers of 3-month-old $p 107^{0 / 0} p 130^{f / f / l}$ and $p 107^{1 / 0} p 130^{-1 /}$ mice were Western blotted for the indicated proteins. Numerical values represent band intensity ratio of apoA-IV relative to vinculin.

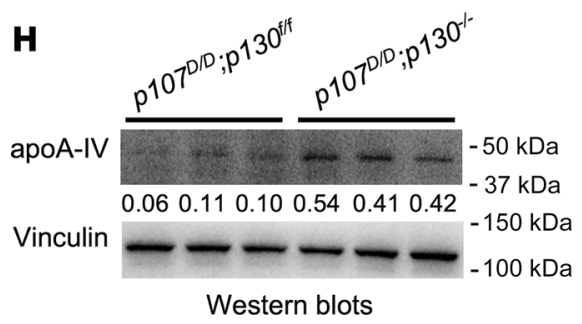

occupancy was accompanied by an increase in B-MYB at the same locations, comparable to what was observed at the Mybl2 promoter (Figure 1C) that is indicative of MYB-MuvB binding (Figure 6, A and $\mathrm{C}$ ). $\mathrm{H} 2 \mathrm{AZ}$ - the histone $\mathrm{H} 2 \mathrm{~A}$ variant that accompanies DREAM-mediated repression in lower organisms (17) - was similarly analyzed. We performed ChIP-qPCR for H2AZ at Apoa1 and Apoa 4 gene bodies and saw a marked decrease in $p 107^{\mathrm{D} / \mathrm{D}} \mathrm{p} 130^{-/}$ livers (Figure 6, A and C). Importantly, Apoa2 and Alb exhibited only background levels of H2AZ that were not altered between genotypes, suggesting that these genes are not bona fide DREAM targets (Figure 6, B and D). Overall, these data provide evidence of direct transcriptional regulation of Apoa1 and Apoa 4 by DREAM/ MYB-MuvB through the CHR and CDE motifs found in their proximal promoters. Furthermore, Apoa1 and Apoa4 lost H2AZ from their gene bodies when DREAM loss was replaced by MYB-MuvB. These data connect DREAM assembly defects to loss of transcriptional control of apolipoprotein genes, which led to protein overexpression and systemic amyloidosis in $107^{\mathrm{D} / \mathrm{D}} \mathrm{p} 130^{-/-}$mice. 


\section{Table 1. LMD/MS analysis of an endpoint $p 107^{0 / 0} p 130^{-/-}$liver}

\begin{tabular}{lc} 
Identified peptides & Per spectral match \\
\hline Apolipoprotein $E^{B}$ & 34 \\
Serum albumin $^{B}$ & 33 \\
Apolipoprotein A-IVA $^{A}$ & 21 \\
Apolipoprotein A-II $^{A}$ & 9 \\
Vitronectin $^{B}$ & 9 \\
Clusterin $^{B}$ & 7 \\
Serum amyloid P-component $^{B}$ & 6 \\
Apolipoprotein A-IA $^{A}$ & 3 \\
Ig $\kappa$ chain & 3 \\
Ig $\mu$ & 3
\end{tabular}

Per spectral match quantities for each protein in the amyloid samples are shown in descending order. ${ }^{A}$ Presumptive amyloidogenic proteins. ${ }^{B}$ Known amyloid-associated proteins.

\section{Discussion}

In the present study, we demonstrated that loss of DREAM assembly led to the development of systemic amyloidosis in adult $p 107^{\mathrm{D} / \mathrm{D}} \mathrm{p} 130^{-/-}$mice. The absence of DREAM increased MYBMuvB recruitment to Apoa1 and Apoa4 promoters and was correlated with reduced $\mathrm{H} 2 \mathrm{AZ}$ levels and overexpression of Apoa1 and Apoa4 genes (Figure 7A). These mice developed extensive amyloid deposition in the heart, kidney, liver, and spleen but not in the brain or bone. Using mass spectrometry, we discovered similar amyloidogenic and amyloid signature proteins in affected organs that implicated apoA-IV as the most likely causative amyloidogenic protein in $p 107^{\mathrm{D} / \mathrm{D}} \mathrm{p} 130^{-/-}$mice (Figure $7 \mathrm{~B}$ ). This condition led to compromised renal function, and likely other organ defects, and a shorter lifespan for $p 107^{\mathrm{D} / \mathrm{D}} \mathrm{p} 13 \mathrm{O}^{-/-}$mice (Figure $7 \mathrm{C}$ ). Overall, this mouse model represents an important milestone in understanding idiopathic amyloidosis cases.

The phenotype of $p 107^{\mathrm{D} / \mathrm{D}} \mathrm{p} 130^{-/-}$mice characterized by AApoAIV amyloidosis includes other provocative similarities with clinical reports of this condition. Amyloid deposition in $p 107^{\mathrm{D} / \mathrm{D}} \mathrm{p} 130^{-/}$ mice was most apparent in kidneys and found throughout the renal interstitium between the cortex and medulla. Similarly, the first reported case for AApoAIV and subsequent analysis of additional patients with AApoAIV revealed extensive amyloid deposition in the interstitial space of the medulla $(16,58)$. LMD/MS analysis of these patients identified apoA-IV as the major constituent of amyloid fibrils in the kidney along with apoE, APCS, and serum albumin $(16,58)$, thus matching our findings here. ApoA-I and immunoglobulin light chain peptides were also present in AApoAIV, but at lower levels $(16,58)$. The involvement of apoE, APCS, and serum albumin in forms of amyloidosis outside of the affected organs observed here further suggests apoA-IV is most likely the causative component of the amyloid. Therefore, our analysis of systemic amyloidosis in $p 107^{\mathrm{D} / \mathrm{D}} \mathrm{p} 130^{-/-}$adult mice is consistent with clinically observed characteristics of AApoAIV. AApoAIV is a newly described form of amyloidosis that has only begun to be appreciated when revealed by LMD/MS analysis. The lack of an underlying mutation in the apoA-IV-encoding gene in these patients has created challenges in identifying the source of this disease and its classification. Our data from $p 107^{\mathrm{D} / \mathrm{D}} \mathrm{p} 130^{-/-}$mice indicate that apolipoprotein misexpression and amyloid deposition may result from a host of different sources that converge on $\mathrm{H} 2 \mathrm{AZ}$ regulation and underscore our finding of this epigenetic source of amyloidosis.

Unlike hereditary amyloidosis caused by apoA-I or apoA-II whereby genetic mutations in Apoa1 or Apoa2 lead to $\alpha$-helix to $\beta$-sheet conformational changes in protein structure that ultimately manifest as amyloid fibrils (5), no such genetic variants have been implicated in AApoAIV (15). Binding with HDL or protein-protein interactions are thought to protect apoA-IV's amyloidogenic hotspot regions within its core $\alpha$-helices (5). It can therefore be surmised that overexpression of Apoa4 may create an imbalance in the concentration of apoA-IV compared with its partner lipids or proteins, thereby increasing the propensity to form amyloid fibrils. Herein, we showed that loss of DREAM assembly in $p 107^{\mathrm{D} / \mathrm{D}} \mathrm{p} 130^{-/-}$mice led to consistent overexpression of Apoa 4 at every age we investigated, whereas Apoa1 overexpression only occurred in 3-month-old mice. We observed a direct interaction of p107 and B-MYB with the Apoa1 and Apoa4 TSSs, which contain putative CHR and CDE sites (20). It is known that loss of DREAM causes a dynamic shift in which the transcriptional activator MYB-MuvB occupies the start site and activates expression $(23,36)$. Our data demonstrated this switch occurred with a concomitant reduction of the $\mathrm{H} 2 \mathrm{AZ}$ repressive mark within Apoa1 and Apoa4 gene bodies. This suggests that these are specific and important DREAM target genes and that a combination of $\mathrm{H} 2 \mathrm{AZ}$ reduction and MYB-MuvB activation increases their expression. Prior work on worms and flies established DREAM as a regulator of gonadal and sex-specific gene expression in addition to cell-cycle control (59); our study indicates that apolipoprotein gene expression is a critical category of DREAM target genes required in mammalian physiology.

In this study, we have shown that DREAM loss and gain of MYB-MuvB activated expression of Apoa4 to drive AApoAIV-mediated amyloidosis. This suggests that enhancement of DREAM or attenuation of B-MYB may offer therapeutic benefit in treating AApoAIV. Additionally, understanding other epigenetic regulators that may help to control H2AZ deposition levels at these genes are also potential targets to ameliorate expression of amyloidosis-causing apolipoprotein genes in the future.

\section{Methods}

Mouse genetics. We utilized our mice that were homozygous for $R b l 1^{\text {tm1.1Fad }}$ (referred to as $p 107^{D / D}$, ref. 36) and Rbl2 ${ }^{\text {tm2.1Tyj }}$ (referred to as $p 130^{f / f l}$, The Jackson Laboratory, stock 008177, ref. 35), in which exon 2 of $p 130$ was flanked by loxP sites. Experimental mice possessed the Ndor1 ${ }^{\text {Tg(UBC-cre/ERT2)IEjb }}$ transgene (38) that was also obtained from The Jackson Laboratory (stock 007001); control animals were $p 107^{\mathrm{D} / \mathrm{D}} \mathrm{p} 130^{f / f l}$. All mice received i.p. administration of tamoxifen at 8 weeks of age $(75 \mathrm{mg} / \mathrm{kg}$ body weight administered in corn oil every 24 hours for 3 consecutive days). This experimental design with a Cre-deficient cohort allowed us to control for potential tamoxifeninduced liver injury in this study $(60,61)$.

Genotyping p130 exon 2 deletion in mice. DNA was isolated from the tail, muscle, liver, heart, brain, testis, and bone from mice 1 week and approximately 2 years after tamoxifen administration. PCR was performed to amplify the region surrounding exon 2 , and the prod- 
A

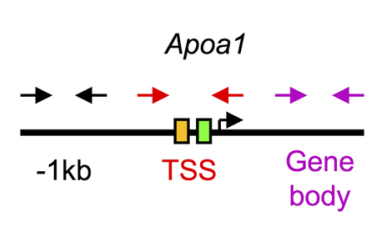

B
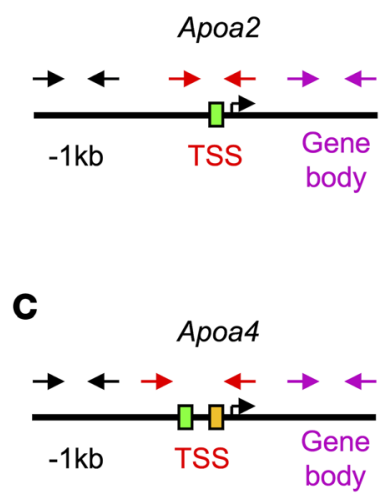

D

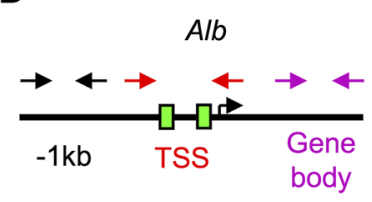

$\square$ Putative CHR motif

$\square$ Putative CDE motif p107
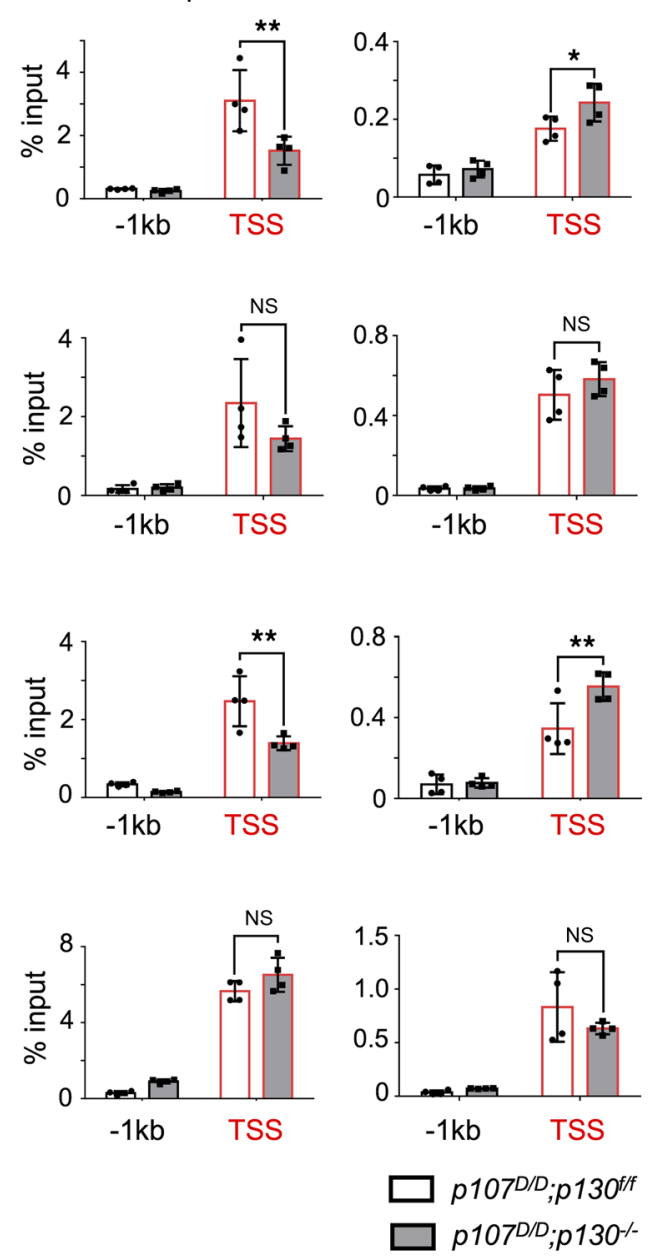
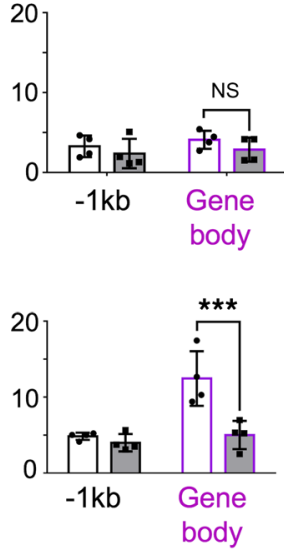

$\mathrm{H} 2 \mathrm{AZ}$
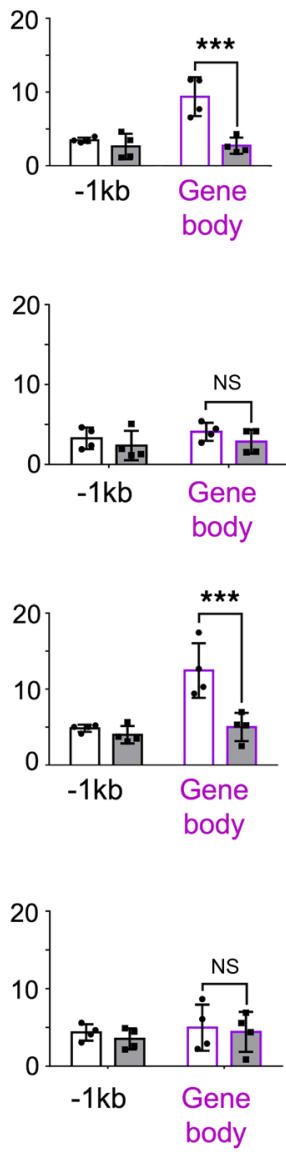

Figure 6. B-MYB is recruited to Apoa1 and Apoa 4 promoters in DREAM assembly-deficient $p 107^{0 / 0} p 130^{-/-}$mice. (A-D) Chromatin was prepared from livers of 3-month-old $p 107^{D / D} p 130^{f / f f}$ and $p 107^{D / D} p 130^{-/-}$mice and utilized in ChIP assays to detect $\mathrm{p} 107^{D}$, B-MYB, and H2AZ occupancy at promoters ( $n=$ 4). For each of Apoa1 (A), Apoa2 (B), Apoa4 (C), and Alb (D) genes, a schematic is shown to illustrate primer annealing sites. Arrows depicting primers are color coded: black represents a neutral location $1 \mathrm{~kb}$ upstream of the TSS; red is an approximately 100 bp region encompassing the CHR and/or CDE motifs near the TSS; purple is within the gene body. ChIP protein targets p107, B-MYB, and H2AZ are organized in columns across the top. Bar graphs depict the mean quantity of chromatin associated with each protein target as detected by qPCR and error bars represent 1 standard deviation. Two-way ANOVA was performed for each graph and significance levels are indicated ( ${ }^{*} P<0.05$; ${ }^{* *} P<0.01$; ${ }^{* *} P<0.001$; and NS, $P>0.05$ ).

ucts were resolved on agarose gels using standard protocols. Primer sequences are listed in Supplemental Table 1.

Western blotting. Tissues were collected from mice and homogenized using an automatic homogenizer in complete RIPA buffer with protease inhibitors (MilliporeSigma, S8820) and incubated for 1 hour on ice. Samples were centrifuged at $12,000 \mathrm{~g}$ in a $4^{\circ} \mathrm{C}$ centrifuge. The supernatant was collected, and protein concentration was determined by Bradford assay. Lysates were mixed with $6 \times$ SDS loading dye buffer and resolved using standard SDS-PAGE protocols in $8 \%$ acrylamide gels. Antibodies used for blotting were p107 (MyBioSource, anti-p107 rabbit antibody MBS440044), p130 (Santa Cruz Biotechnology, antip130 rabbit antibody SC-317), apoA-IV (Cell Signaling Technology, anti-ApoA4 mouse antibody 5700), tubulin (Cell Signaling Technology, anti-tubulin rabbit antibody 2125), and vinculin (Cell Signaling Technology, anti-vinculin rabbit antibody 4650). Band intensities were measured and analyzed in Image J, version $1.53 \mathrm{c}(\mathrm{NIH})$.
ChIP. ChIP assay was performed as described previously $(62,63)$. Livers were harvested from 3-month-old $p 107^{\mathrm{D} / \mathrm{D}} p 130^{f / f l}$ and $p 107^{\mathrm{D} / \mathrm{D}}$ $p 130^{-/-}$mice midmorning. Livers were weighed and cut into $60 \mathrm{mg}$ pieces that were then homogenized in ice-cold PBS using an automatic homogenizer. Samples were incubated with $1 \%$ formaldehyde for 10 minutes on a rotator at room temperature. Samples were then sonicated. Next, $50 \mu \mathrm{L}$ protein A/G Dynabeads (Invitrogen, Thermo Fisher Scientific) were premixed with ChIP antibodies (p107: $10 \mu \mathrm{g}$, MyBioSource, anti-p107 rabbit antibody MBS440044; B-MYB: $10 \mu \mathrm{g}$, MilliporeSigma, anti-B-MYB mouse antibody MABE886; H2AZ: $5 \mu \mathrm{g}$, Abcam, anti-histone H2A.Z rabbit antibody ab4174), and then combined with lysed and sonicated samples and incubated overnight at $4{ }^{\circ} \mathrm{C}$ with rotation. Dynabeads were then washed and chromatin was eluted using elution buffer (1\% SDS, $0.1 \mathrm{M} \mathrm{NaHCO}_{3}$ ), and after de-crosslinking DNA was isolated. The resulting ChIP DNA was analyzed by qPCR (as described above) with primer pairs designed to amplify $-1 \mathrm{~kb}$ 
A
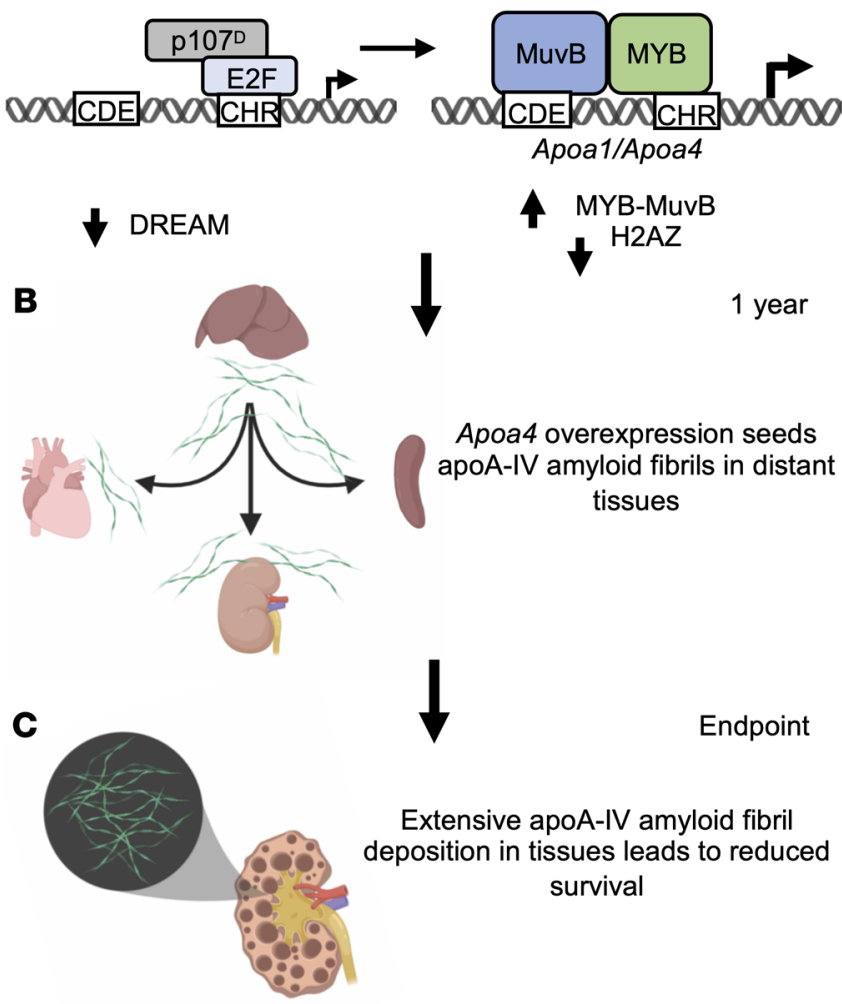

upstream of the TSS (neutral location), primers to amplify the proximal promoter regions, and primers to amplify within the gene bodies of Apoa1, Apoa2, Apoa4, Alb, and Mybl2 (Supplemental Table 1).

Ccna2 promoter pulldown. Primer pairs (Supplemental Table 1) were used to amplify the promoter region of Ccna2 containing a CDE and a CHR and $A c t b$, such that only 1 primer was biotinylated, resulting in the amplicon being biotinylated at 1 end. These were purified using a PCR cleanup kit (Invitrogen, Thermo Fisher Scientific). Dynabeads were washed and prepared in $2 \times$ binding and washing buffer $(10 \mathrm{mM}$ Tris- $\mathrm{HCl} \mathrm{pH} \mathrm{7.5,} 1$ mM EDTA, $2 \mathrm{M} \mathrm{NaCl}$ ). An equal volume of purified PCR fragments in nuclease-free water was added and incubated for 15 minutes at room temperature on a rotator. Dynabeads were then washed $3 \times$ with $1 \times$ binding and washing buffer and after the final wash, all buffers were removed from the tube. Lysates were obtained from livers of 3-month-old $p 107^{\mathrm{D} / \mathrm{D}} p 130^{f / f l}$ and $p 107^{\mathrm{D} / \mathrm{D}} \mathrm{p130^{-/- }}$ mice as described above. Next, $1 \mathrm{mg}$ of protein in RIPA lysis buffer was added to the Dynabeads as well as $0.1 \mu \mathrm{L}$ of $10 \% \mathrm{NP}-40$ and mixed overnight at $4^{\circ} \mathrm{C}$. Dynabeads were then washed twice in lysis buffer and $50 \mu \mathrm{L}$ release buffer (10 mM EDTA pH 8.2 with $95 \%$ formamide) was added and incubated for 2 minutes at $90^{\circ} \mathrm{C}$. Supernatant containing bound proteins was collected, $5 \times$ SDS loading dye was added, and proteins were resolved by SDS-PAGE and identified by Western blotting.

Tissue preparation and staining. Mice were either aged until their endpoints or euthanized at an earlier time point. The following organs were collected and fixed in formalin: brain, heart, lungs, liver, kidney, spleen, ovaries, testes, and lymph nodes. Tissues were processed and sectioned in the Molecular Pathology Core Facility at Robarts Research Institute. Staining with H\&E or Congo red was carried out by the core facility using standard methods.
Figure 7. Loss of DREAM assembly in $\mathrm{p}^{107^{0 / 0}} \mathrm{p} 130^{-/-}$mice promotes MYB-MuvB assembly that drives systemic AApoAIV amyloidosis due to constitutive overexpression of Apoa4. A schematic model illustrating the

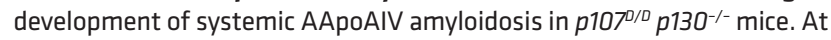
3 months of age, ablation of p130 by Cre activation combined with mutant p107 prevents DREAM assembly and promotes MYB-MuvB activation of transcription. In the liver, MYB-MuvB occupies CHR and CDE motifs at the TSSs of apolipoprotein genes, particularly Apoa4, leading to reduced H2AZ occupancy within its gene body and constitutive overexpression (A). In 1-year-old $p 107^{0 / 0} p 130^{-/-}$mice, small amyloid deposits are evident in the heart, liver, kidney, and spleen (B). By 2 years of age, apoA-IV deposition was more pronounced in the heart, liver, and spleen. Deposition in the kidney of most $p 107^{0 / 0} p_{130^{-/-}}$mice led to organ failure and reduced survival (C).

Scoring amyloid damage to tissues. Tissues stained with H\&E or Congo red were scored for amyloid deposition, cellular degeneration, and inflammation each on a scale of 0-3 as per the criteria shown in Supplemental Figure 6. Cumulative scores from all 3 categories were used to determine an aggregated, semiquantitative pathology score for each tissue and timepoint.

Proteinuria assay. Urine from mice was collected and assayed for protein as previously described (44). Briefly, urine was directly collected into $1.5 \mathrm{~mL}$ tubes. Nine parts urine was mixed with 1 part 10× SDS loading dye buffer. Next, $10 \mu \mathrm{L}$ urine per mouse was resolved by SDS-PAGE gels and proteins were stained with Coomassie blue to visualize proteins.

Creatinine assay. Whole blood was collected through cardiac puncture from approximately 2-year-old endpoint mice. Blood was allowed to clot undisturbed at room temperature for 15 minutes, and the clot was removed by centrifugation at $2000 \mathrm{~g}$ for 15 minutes to separate serum. Serum was diluted 1:1000 and assayed in triplicates using Abcam creatinine assay kit (ab65340). Samples were measured fluorometrically using a Wallac 1420 Victor 2 microplate reader (PerkinElmer Informatics) at Ex/Em 538/587 nm.

Protein identification. MALDI-MS was performed at the London Regional Proteomics Centre. Briefly, Coomassie blue-stained bands were excised and gel-digested using a MassPREP automated digester (PerkinElmer). Peptides were ionized with an AB Sciex 5800 TOF/ TOF using a TOF/TOF Series Explorer data acquisition system. Protein identification was made using the Mascot search engine.

TEM. TEM was performed at the Biotron of Western University on paraffin-embedded tissue blocks. Fragments of paraffin-embedded tissue were cut into $1 \mathrm{~mm}^{3}$ pieces using a biopsy punch. Using the methods of Lighezan et al. (64), tissues were deparaffinized in xylene 3 times for 30 minutes at room temperature. Specimens were then rehydrated in a descending series of ethanol solutions followed by rinsing in $0.1 \mathrm{M}$ cacodylate buffer for 10 minutes. Tissues were then postfixed in a 3\% glutaraldehyde in $0.1 \mathrm{M}$ cacodylate buffer ( $\mathrm{pH}$ 7.4) overnight ( $\sim 12$ hours) at $4^{\circ} \mathrm{C}$ and then rinsed in $0.1 \mathrm{M}$ cacodylate buffer. Postfixation was carried out for 1 hour with $1.0 \%$ osmium tetroxide in $0.1 \mathrm{M}$ cacodylate buffer. Specimens were dehydrated in an ascending series of ethanol solutions and embedded in Spurr's resin at $60^{\circ} \mathrm{C}$ for 2 days. Ultrathin $(70 \mathrm{~nm})$ sections were cut using an ultramicrotome (Ultramicrotome Reichert-Jung Ultracut E; Leica Microsystems). Imaging was carried out using a Philips CM10 transmission electron microscope (Philips Electron Optics), and amyloid fiber diameters were measured using CM10 image analysis software.

Amyloid subtyping by LMD/MS. Sample preparation and proteomics analysis were performed at University Health Network's Laboratory 
Medicine Program (Toronto, Canada). A modified method previously published by Dogan et al. (65), was used for protein extraction from mouse tissue. Briefly, a $10 \mu \mathrm{m}$ thick section of FFPE tissue was mounted on a Director slide (NantOmics) and stained with Congo red. Amyloid-positive regions were then extracted with the LMD7000 system (Leica Microsystems) and collected via gravity in caps of $0.5 \mathrm{~mL}$ microtubes containing $35 \mu \mathrm{L}$ of protein extraction buffer (mix of $10 \mathrm{mM}$ Tris, $1 \mathrm{mM}$ EDTA, and 0.002\% Zwittergent 3-16 [Calbiochem]). After tissue collection, microtubes were centrifuged for 2 minutes at $9295 \mathrm{~g}$ (Eppendorf microcentrifuge, $5417 \mathrm{C}$ ). To extract proteins from FFPE matrix, we heated the samples at $98^{\circ} \mathrm{C}$ for 90 minutes with occasional vortexing. Samples were then sonicated in a water bath for 1 hour (VWR Scientific Aquasonic, P250D), and then digested with $0.5 \mu \mathrm{g}$ trypsin (Promega) overnight at $37^{\circ} \mathrm{C}$. Digested samples were reduced with $2 \mu \mathrm{L}$ of $0.1 \mathrm{M}$ dithiothreitol at $95^{\circ} \mathrm{C}$ for 5 minutes and diluted with $7 \mu \mathrm{L}$ of $0.5 \%$ trifluoroacetic acid and $0.15 \%$ formic acid solution made in LC-MS grade water. Next, $18 \mu \mathrm{L}$ of sample was analyzed using nanoflow liquid chromatography-tandem mass spectrometry (nLC-MS/MS).

All samples were analyzed using a hybrid LTQ Orbitrap XL mass spectrometer coupled to an Easy nLC 1000 liquid chromatography system (Thermo Fisher Scientific). Peptides were applied to a trap C8 column $(150 \mu \mathrm{m}$ ID $\times 20$ mm, New Objective; $5 \mu \mathrm{m}$ Magic C8 packing, Michrom Bioresources) and separated on a reverse phase C18 column (75 $\mu \mathrm{m}$ ID $\times 150$ mm, New Objective; $3 \mu \mathrm{m}$ Agilent Pursuit C18 packing, Agilent Technologies) using a linear gradient from $1 \%$ to $65 \%$ acetonitrile containing $0.1 \%$ formic acid over 112 minutes at a flow rate of $300 \mathrm{~nL} / \mathrm{min}$. Eluting peptides were ionized using Nanospray Flex Ion source (Thermo Fisher Scientific), and the corresponding spectra in the positive ion mode were obtained under data-dependent acquisition mode. Full MS scans were collected in the orbitrap (400-1500 $\mathrm{m} / \mathrm{z}$ range, 60,000 resolution), while the top 7 most intense precursor ions that underwent collisionally induced dissociation at $35 \mathrm{~V}$ were detected by the linear ion trap.

The resulting raw data files were processed using the Proteome Discoverer 1.4 (Thermo Fisher Scientific) and the Sequest HT algorithm. The fragmentation spectra were searched against the UniProt Mus musculus database (last modified January 15, 2020). The search parameters were as follows: the precursor mass tolerance was $7 \mathrm{ppm}$ and the fragment mass tolerance was set to $\pm 0.05 \mathrm{Da}$. The peptide FDR was less than $1 \%$. Peptides associated with a high confidence level identification (probability of identification $>90 \%$ ) were filtered and selected for protein identification.

$R T-q P C R$. Tissues were collected from mice at different time points (3-month-old, 1-year-old, and endpoint mice) and processed using the Monarch Total RNA Miniprep Kit (NEB T2010S). RNA was reverse transcribed using iScript (Bio-Rad, 1708891) and cDNA was diluted $5 \times$ with nuclease-free water. Real-time qPCR was performed for Apoa1, Apoa2, Apoa4, Alb, Apoe, Apcs, and Ighm using PowerUP SYBR (Applied Biosystems, A25742). Gapdh was used as the internal control. Primer sequences are available in Supplemental Table 1.

Statistics. Specific statistical tests used are indicated in the figure legends for each experiment. Analysis was done using GraphPad Prism version 7. A $P$ value of less than 0.05 was considered significant.

Study approval. All animal experiments were approved by the Animal Care Committee (ACC) of Western University in accordance with regulations from the Canadian Council on Animal Care.

\section{Author contributions}

PP participated in study design, carried out experiments in all figures, and wrote the manuscript. $\mathrm{HMH}$ participated in study design, experiments in Figure $1 \mathrm{C}$ and Figure 6, and edited the manuscript. GEL carried out experiments in Figure 2D. DTP participated in experiments in Figure 1 and Supplemental Figures 1 and 2. JT participated in study design, Figure 1C and Figure 6, and edited the manuscript. PKK participated in study design, data analysis in Figures 2 and 3, and Supplemental Figures 4-6 and 9, and helped write the manuscript. AB and VK carried out experiments in Figure 5, C-E, and helped write the manuscript. FAD participated in study design, data analysis, and wrote the manuscript.

\section{Acknowledgments}

The authors wish to thank G. DiMattia, M. Huff, and M. Cecchini for experimental and analytical advice throughout the course of this work. We are also greatly indebted to colleagues in the Biotron, Molecular Pathology Core, and London Regional Proteomics Centre at Western University for services. Illustrations were created in BioRender.com. PP was supported by the Strategic Training Program in Cancer Research. GEL was a recipient of a dean's undergraduate research opportunity fellowship. FAD is the Wolfe Senior Fellow in Tumor Suppressor Genes at Western University. This work was supported by grants from the Canadian Cancer Society Research Institute (CCSRI) (702983, to FAD) and the Canadian Institutes of Health Research (CIHR) (MOP 324579 to FAD).

Address correspondence to: Fred Dick, Cancer Research Labs, 790 Commissioners Road East, London, Ontario N6A 4L6, Canada. Phone: 519.685.8500 ext.53027; Email: fdick@uwo.ca.
1. Wechalekar $\mathrm{AD}$, et al. Systemic amyloidosis. The Lancet. 2016;387(10038):2641-2654.

2. Benson MD, et al. Amyloid nomenclature 2018: recommendations by the International Society of Amyloidosis (ISA) nomenclature committee. Amyloid. 2018;25(4):215-219.

3. Luo H, et al. Extracellular deposition of mouse senile AApoAII amyloid fibrils induced different unfolded protein responses in the liver, kidney, and heart. Lab Invest. 2015;95(3):320-333.

4. Nuvolone M, Merlini G. Systemic amyloidosis: novel therapies and role of biomarkers. Nephrol Dial Transplant. 2017;32(5):770-780.

5. Das M, Gursky O. Amyloid-forming properties of human apolipoproteins: sequence analyses and structural insights. Adv Exp Med Biol. 2015;855:175-211.

6. Lamon-Fava S, Micherone D. Regulation of apoA-I gene expression: mechanism of action of estrogen and genistein. J Lipid Res. 2004;45(1):106-112.

7. Wang Y, et al. ApoA-I deficiency in mice is associated with redistribution of apoA-II and aggravated AApoAII amyloidosis. J Lipid Res. 2011;52(8):1461-1470.

8. Lu C, et al. Apolipoprotein A-1-related amyloidosis 2 case reports and review of the literature. Medicine (Baltimore). 2017;96(39):e8148.
9. Ge F, et al. Amyloidosis in transgenic mice expressing murine amyloidogenic apolipoprotein A-II (Apoa2c). Lab Invest. 2007;87(7):633-643.

10. Nakamura T, et al. Transcription factors and age-related decline in apolipoprotein A-I expression. J Lipid Res. 1999;40(9):1709-1718.

11. Wang Z, et al. Apolipoprotein A-IV involves in glucose and lipid metabolism of rat. Nutr Metab (Lond). 2019;16:41.

12. Tubb MR, et al. A three-dimensional homology model of lipid-free apolipoprotein A-IV using cross-linking and mass spectrometry. J Biol Chem. 2008;283(25):17314-17323.

13. Walker RG, et al. The structure of human 
apolipoprotein A-IV as revealed by stable isotope-assisted cross-linking, molecular dynamics, and small angle $\mathrm{x}$-ray scattering. J Biol Chem. 2014;289(9):5596-5608.

14. Mollee $\mathrm{P}$, et al. Implementation and evaluation of amyloidosis subtyping by laser-capture microdissection and tandem mass spectrometry. Clin Proteomics. 2016;13:30.

15. Obici L, et al. Expanding the spectrum of systemic amyloid diseases: a new hint from the kidney. Kidney Int. 2016;90(3):479-481.

16. Sethi S, et al. Medullary amyloidosis associated with apolipoprotein A-IV deposition. Kidney Int. 2012;81(2):201-206.

17. Latorre I, et al. The DREAM complex promotes gene body H2A.Z for target repression. Genes Dev. 2015;29(5):495-500.

18. Creyghton MP, et al. H2AZ is enriched at polycomb complex target genes in ES cells and is necessary for lineage commitment. Cell. 2008;135(4):649-661.

19. Sevilla A, Binda O. Post-translational modifications of the histone variant H2AZ. Stem Cell Res. 2014;12(1):289-295.

20. Muller GA, et al. The CHR site: definition and genome-wide identification of a cell cycle transcriptional element. Nucleic Acids Res. 2014;42(16):10331-10350.

21. Sadasivam S, DeCaprio JA. The DREAM complex: master coordinator of cell cycle-dependent gene expression. Nat Rev Cancer. 2013;13(8):585-595.

22. Mages CF, et al. The DREAM complex through its subunit $\operatorname{Lin} 37$ cooperates with $\mathrm{Rb}$ to initiate quiescence. Elife. 2017;6:e26876.

23. Litovchick L, et al. Evolutionarily conserved multisubunit RBL2/p130 and E2F4 protein complex represses human cell cycle-dependent genes in quiescence. Mol Cell. 2007;26(4):539-551.

24. Ceol CJ, Horvitz HR. dpl-1 DP and efl-1 E2F act with lin-35 Rb to antagonize Ras signaling in C. elegans vulval development. Mol Cell. 2001;7(3):461-473.

25. Fay DS, Han M. The synthetic multivulval genes of C. elegans: functional redundancy, Rasantagonism, and cell fate determination. Genesis. 2000;26(4):279-284.

26. Korenjak M, et al. Native E2F/RBF complexes contain Myb-interacting proteins and repress transcription of developmentally controlled E2F target genes. Cell. 2004;119(2):181-193.

27. Lewis PW, et al. Identification of a Drosophila Myb-E2F2/RBF transcriptional repressor complex. Genes Dev. 2004;18(23):2929-2940.

28. Schmit F, et al. LINC, a human complex that is related to pRB-containing complexes in invertebrates regulates the expression of $\mathrm{G} 2 / \mathrm{M}$ genes. Cell Cycle. 2007;6(15):1903-1913.

29. Sadasivam S, et al. The MuvB complex sequentially recruits B-Myb and FoxM1 to promote mitotic gene expression. Genes Dev. 2012;26(5):474-489.

30. Pilkinton M, et al. Mammalian Mip/LIN-9 interacts with either the p107, p130/E2F4 repressor complex or B-Myb in a cell cycle-phase-dependent context distinct from the Drosophila dREAM complex. Oncogene. 2007;26(54):7535-7543.
31. Cobrinik D, et al. Shared role of the pRB-related p130 and p107 proteins in limb development. Genes Dev. 1996;10(13):1633-1644.

32. Reichert N, et al. Lin9, a subunit of the mammalian DREAM complex, is essential for embryonic development, for survival of adult mice, and for tumor suppression. Mol Cell Biol. 2010;30(12):2896-2908.

33. Gaubatz S, et al. E2F 4 and E2F5 play an essential role in pocket protein-mediated G1 control. Mol Cell. 2000;6(3):729-735.

34. Kohn MJ, et al. Dp1 is required for extraembryonic development. Development. 2003;130(7):1295-1305.

35. MacPherson D, et al. Murine bilateral retinoblastoma exhibiting rapid-onset, metastatic progression and $\mathrm{N}$-mycgene amplification. $E M B O \mathrm{~J}$. 2007;26(3):784-794.

36. Forristal C, et al. Loss of the mammalian DREAM complex deregulates chondrocyte proliferation. Mol Cell Biol. 2014;34(12):2221-2234.

37. Guiley KZ, et al. Structural mechanisms of DREAM complex assembly and regulation. Genes Dev. 2015;29(9):961-974.

38. Ruzankina Y, et al. Deletion of the developmentally essential gene ATR in adult mice leads to age-related phenotypes and stem cell loss. Cell Stem Cell. 2007;1(1):113-126.

39. MacDonald J, et al. A systematic analysis of negative growth control implicates the DREAM complex in cancer cell dormancy. Mol Cancer Res. 2017;15(4):371-381.

40. Fischer M, et al. The p53-p21-DREAM-CDE/ CHR pathway regulates $\mathrm{G} 2 / \mathrm{M}$ cell cycle genes. Nucleic Acids Res. 2016;44(1):164-174.

41. Kuroda T, et al. Significant association between renal function and area of amyloid deposition evident in kidney biopsy specimens in both AA and AL amyloidosis. Amyloid. 2017;24(sup1):151-152.

42. Erdogmus S, et al. Profile of renal AA amyloidosis in older and younger individuals: a single-centre experience. Amyloid. 2018;25(2):115-119.

43. Sethi S, Theis JD. Pathology and diagnosis of renal non-AL amyloidosis. J Nephrol. 2018;31(3):343-350.

44. Guo X, et al. Two predominant MUPs, OBP3 and MUP13, are male pheromones in rats. Front Zool. 2018;15:6.

45. Tougaard BG, et al. A case report of hereditary apolipoprotein A-I amyloidosis associated with a novel APOA1 mutation and variable phenotype. Eur J Med Genet. 2016;59(9):474-477.

46. Sipe JD, et al. Amyloid fibril proteins and amyloidosis: chemical identification and clinical classification International Society of Amyloidosis 2016 Nomenclature Guidelines. Amyloid 2016;23(4):209-213.

47. Clement CG, Truong LD. An evaluation of Congo red fluorescence for the diagnosis of amyloidosis. Hum Pathol. 2014;45(8):1766-1772.

48. Menter T, et al. A more accurate approach to amyloid detection and subtyping: combining in situ Congo red staining and immunohistochemistry. Pathobiology. 2017;84(1):49-55.

49. Sunde M, et al. Common core structure of amy- loid fibrils by synchrotron X-ray diffraction. J Mol Biol. 1997;273(3):729-739.

50. Lundmark K, et al. Depletion of spleen macrophages delays AA amyloid development: a study performed in the rapid mouse model of AA amyloidosis. PLoS One. 2013;8(11):e79104.

51. Sen S, Sarsik B. A proposed histopathologic classification, scoring, and grading system for renal amyloidosis: standardization of renal amyloid biopsy report. Arch Pathol Lab Med. 2010;134(4):532-544.

52. Vrana JA, et al. Classification of amyloidosis by laser microdissection and mass spectrometrybased proteomic analysis in clinical biopsy specimens. Blood. 2009;114(24):4957-4959.

53. Abildgaard $\mathrm{N}$, et al. Immunoelectron microscopy and mass spectrometry for classification of amyloid deposits. Amyloid. 2020;27(1):59-66.

54. Vrana JA, et al. Clinical diagnosis and typing of systemic amyloidosis in subcutaneous fat aspirates by mass spectrometry-based proteomics. Haematologica. 2014;99(7):1239-1247.

55. Miyahara $\mathrm{H}$, et al. Comprehensive proteomic profiles of mouse AApoAII amyloid fibrils provide insights into the involvement of lipoproteins in the pathology of amyloidosis. J Proteomics. 2018;172:111-121.

56. Brambilla F, et al. Shotgun protein profile of human adipose tissue and its changes in relation to systemic amyloidoses. J Proteome Res. 2013;12(12):5642-5655.

57. Blanc $\mathrm{P}$, et al. Mature IgM-expressing plasma cells sense antigen and develop competence for cytokine production upon antigenic challenge. Nat Commun. 2016;7:13600.

58. Dasari S, et al. Clinical, biopsy, and mass spectrometry characteristics of renal apolipoprotein A-IV amyloidosis. Kidney Int. 2016;90(3):658-664.

59. Dimova DK, et al. Cell cycle-dependent and cell cycle-independent control of transcription by the Drosophila E2F/RB pathway. Genes Dev. 2003;17(18):2308-2320.

60. Blackburn AM, et al. Tamoxifen and liver damage. Br Med J (Clin Res Ed). 1984;289(6440):288

61. Gao F-F, et al. Tamoxifen induces hepatotoxicity and changes to hepatocyte morphology at the early stage of endocrinotherapy in mice. Biomed Rep. 2016;4(1):102-106.

62. Hassan HM, et al. Regulation of active DNA demethylation through RAR-mediated recruitment of a TET/TDG complex. Cell Rep. 2017;19(8):1685-1697.

63. Thillainadesan $\mathrm{G}$, et al. TGF- $\beta$-dependent active demethylation and expression of the p15ink $4 \mathrm{~b}$ tumor suppressor are impaired by the ZNF217/ CoREST complex. Mol Cell. 2012;46(5):636-649.

64. Lighezan $\mathrm{R}$, et al. The value of the reprocessing method of paraffin-embedded biopsies for transmission electron microscopy. Rom J Morphol Embryol. 2009;50(4):613-617.

65. Rodriguez FJ, et al. Immunoglobulin derived depositions in the nervous system: novel mass spectrometry application for protein characterization in formalin-fixed tissues. Lab Invest. 2008;88(10):1024-1037. 